OPEN ACCESS

Edited by:

Vladimir Lesnyak,

Technische Universität Dresden,

Germany

Reviewed by:

Sergey V. Gaponenko,

BI Stepanov Institute of Physics

(NASB), Belarus

Zhenmeng Peng,

University of Akron, United States

*Correspondence:

Hongbo L

hbli@mail.ipc.ac.cn

Specialty section: This article was submitted to Nanoscience,

a section of the journal

Frontiers in Chemistry

Received: 28 September 2018 Accepted: 13 December 2018

Published: 08 January 2019

Citation:

Li H, Jia C, Meng X and Li H (2019) Chemical Synthesis and Applications

of Colloidal Metal Phosphide

Nanocrystals. Front. Chem. 6:652.

doi: 10.3389/fchem.2018.00652

\section{Chemical Synthesis and Applications of Colloidal Metal Phosphide Nanocrystals}

\author{
Hui Li ${ }^{1}$, Chao Jia ${ }^{1}$, Xianwei Meng ${ }^{2}$ and Hongbo $\mathrm{Li}^{{ }^{*}}$ \\ ${ }^{1}$ Beijing Key Laboratory of Construction-Tailorable Advanced Functional Materials and Green Applications, School of \\ Materials Science \& Engineering, Beijing Institute of Technology, Beijing, China, ${ }^{2}$ Laboratory of Controllable Preparation and \\ Application of Nanomaterials, CAS Key Laboratory of Cryogenics, Technical Institute of Physics and Chemistry, Chinese \\ Academy of Sciences, Beijing, China
}

Colloidal nanocrystals (NCs) have emerged as promising materials in optoelectronic devices and biological imaging application due to their tailorable properties through size, shape, and composition. Among these NCs, metal phosphide is an important class, in parallel with metal chalcogenide. In this review, we summarize the recent progress regarding the chemical synthesis and applications of colloidal metal phosphide NCs. As the most important metal phosphide NCs, indium phosphide (InP) NCs have been intensively investigated because of their low toxicity, wide and tunable emission range from visible to the near-infrared region. Firstly, we give a brief overview of synthetic strategies to InP NCs, highlighting the benefit of employing zinc precursors as reaction additive and the importance of different phosphorus precursors to improve the quality of the InP NCs, in terms of size distribution, quantum yield, colloidal stability, and non-blinking behavior. Next, we discuss additional synthetic techniques to overcome the issues of lattice mismatch in the synthesis of core/shell metal phosphide NCs, by constructing an intermediate layer between core/shell or designing a shell with gradient composition in a radial direction. We also envision future research directions of InP NCs. The chemical synthesis of other metal phosphide NCs, such as II-V metal phosphide NCs $\left(\mathrm{Cd}_{3} \mathrm{P}_{2}, \mathrm{Zn}_{3} \mathrm{P}_{2}\right)$ and transition metal phosphides $\mathrm{NCs}\left(\mathrm{Cu}_{3} \mathrm{P}, \mathrm{FeP}\right)$ is subsequently introduced. We finally discuss the potential applications of colloidal metal phosphide NCs in photovoltaics, light-emitting diodes, and lithium ion battery. An overview of several key applications based on colloidal metal phosphide NCs is provided at the end.

Keywords: colloidal nanocrystals, indium phosphide, phosphorus precursors, II-V metal phosphide nanocrystals, transition metal phosphides nanocrystals

\section{INTRODUCTION}

Colloidal nanocrystals (NCs) that exhibit unique optical and electrical properties have attracted considerable attention due to diverse applications such as photovoltaics, optoelectronics, (Coe et al., 2002; Dai et al., 2014; Pietryga et al., 2016; Panfil et al., 2018), and biomedical imaging (Michalet et al., 2005; Hong et al., 2017). Among these NCs, metal phosphide NCs are chemical compounds containing phosphorus and one or more metals, with formula of $\mathrm{M}_{\mathrm{x}} \mathrm{P}_{\mathrm{y}}$. Phosphorus is known to be able to form at least one stable compounds (e.g., $\operatorname{InP}, \mathrm{Cu}_{3} \mathrm{P}$ ) with d-group metals and most of the rare earth metals. Besides, many metal phosphides have multiple stoichiometry, 
providing various crystal structures for binary metal phosphides. Most of the metal phosphide NCs share metal-metalloid bonds (M-P) with a strong covalent component (Greenwood et al., 1966). These bonds are often combined with highly covalent metalloid-metalloid bonds (P-P) (Carenco et al., 2013), where the formation of covalent bond requires harsher reaction conditions for the colloidal chemical synthesis, such as highly active precursors or high reaction temperature. Unlike the metal chalcogenide, metal phosphide can be semiconductors, insulators, and conductors, which are highly dependent on the chemical composition, crystal structure, and electronic state. These specific features provide metal phosphides with unique properties, and also facilitate many potential applications.

Nowadays, conventional cadmium and lead based NCs have been judged because of environmental concerns on heavy metals. Therefore, InP NCs present an attractive alternative owing to low toxicity and emission tunability ranging from visible to nearinfrared region (Ramasamy et al., 2017). Zinc phosphide $\left(\mathrm{Zn}_{3} \mathrm{P}_{2}\right)$ is an intriguing material for photovoltaic (Luber et al., 2013). It has a band gap of $1.5 \mathrm{eV}$, a large absorption coefficient, a long minority-carrier diffusion length. Transition metal phosphides also have great potential in energy conversion and storage applications.

To synthesize colloidal NCs, cationic, and anionic precursors are indispensable with ligands, non-coordinating solvent as well as high temperature exposure to advance reaction. As for anion precursors in metal phosphide NCs, phosphorus precursors that have been used in the colloidal synthesis can be classified into different types, including the single source precursor $\left(\operatorname{In}\left(\mathrm{PBu}_{2}^{\mathrm{t}}\right)_{3}\right)$ (Green and O'Brien, 1998), $\mathrm{P}\left(\mathrm{SiMe}_{3}\right)_{3}$, metal phosphorus $\left(\mathrm{Na}_{3} \mathrm{P}\right)$ (Jun et al., 2006), magic sized clusters (MSCs) (Friedfeld et al., 2017), elemental phosphorus precursor (Ung et al., 2008; Bang et al., 2017), and $\mathrm{PH}_{3}$ gas ( $\mathrm{Zan}$ and Ren, 2012). Figure 1 shows different types of phosphorus precursors that have been applied in the chemical synthesis of metal phosphide NCs. Regardless of investigations of various phosphorus precursors, $\mathrm{P}\left(\mathrm{SiMe}_{3}\right)_{3}$ tend to obtain high quality of InP NCs. However, air and water-free conditions are necessary for the sensitive, hazardous nature of $\mathrm{P}\left(\mathrm{SiMe}_{3}\right)_{3}$. In addition, scalability is also a crucial factor because of the demand of large quantity of NCs in commercial applications. In this case, aminophosphine precursors are found to give access to NCs with comparable characteristics as $\mathrm{P}\left(\mathrm{SiMe}_{3}\right)_{3}$. In the following sections, the reaction mechanism of InP formation with aminophosphine precursors will be summarized. Several colloidal syntheses utilize TOP and $\mathrm{P}\left(\mathrm{SiMe}_{3}\right)_{3}$ to obtain zinc phosphide and transition metal phosphides NCs, which borrow experiences from other metal phosphide NCs (Luber et al., 2013; Ramasamy et al., 2017).

The undercoordinated surface atoms in NC surfaces, acting as trap states, will affect the lifetime, efficiency of electron hole pairs, radiative recombination. Coating an additional shell provides extra means to manipulate the properties. Typically, type I core/shell NCs feature a strongly enhanced photoluminescence quantum yield (PLQY), such as $\mathrm{InP} / \mathrm{ZnS}$, and $\mathrm{InP} / \mathrm{ZnSe}$. Moreover, insert buffer layers $(\mathrm{InP} / \mathrm{GaP} / \mathrm{ZnS})$ or adjust the lattice constant of core and shell ( $\mathrm{InZnP} / \mathrm{ZnSeS})$ can minimize strain

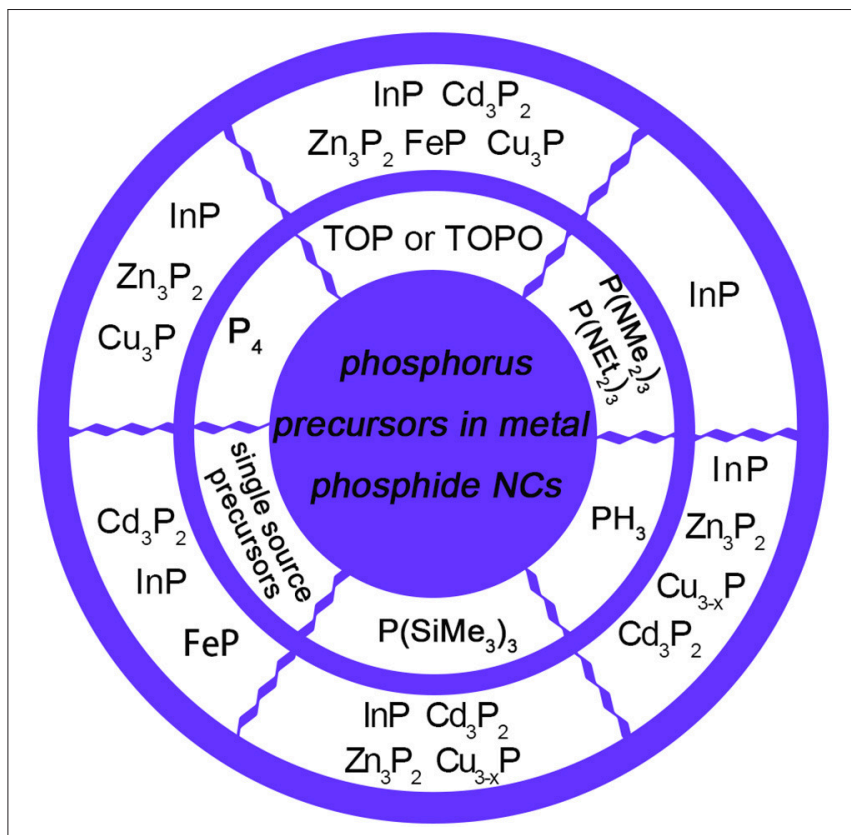

FIGURE 1 | Various types of phosphorus precursors used in the synthesis of metal phosphide NCs. InP NCs could be synthesized by TOP (Lauth et al., 2013), P(NMe $)_{3}$ (Song et al., 2013), P(NEt $)_{3}$ (Tessier et al., 2015), $\mathrm{PH}_{3}$ (Li et al., 2008), $\mathrm{P}\left(\mathrm{SiMe}_{3}\right)_{3}$ (Micic et al., 1994), $\mathrm{P}_{4}$ (Ung et al., 2008), and single source precursors, including $\ln \left(\mathrm{PBu}_{2}^{t}\right)_{3}$ (Green and O'Brien, 1998) and magic-size clusters (MSCs) (Gary et al., 2015). $\mathrm{Zn}_{3} \mathrm{P}_{2}$ NCs could be synthesized by TOP (Mobarok et al., 2014), $\mathrm{PH}_{3}$ (Miao et al., 2013), P(SiMe 3$)_{3}$ (Ho et al., 2015), and $\mathrm{P}_{4}$ (Carenco et al., 2010). $\mathrm{Cd}_{3} \mathrm{P}_{2}$ NCs could be synthesized by TOP (Khanna et al., 2010), $\mathrm{PH}_{3}$ (Miao et al., 2012), $\mathrm{P}\left(\mathrm{SiMe}_{3}\right)_{3}$ (Miao et al., 2010), and MSCs (Li et al., 2014) acting as single source precursors. FeP could be synthesized by TOP (Henkes and Schaak, 2007) and $(\mathrm{CO})_{4} \mathrm{Fe}\left(\mathrm{PH}_{3}\right)$ (Hunger et al., 2013) acting as single source precursors. Copper phosphides could be synthesized by TOP (Henkes and Schaak, 2007), $\mathrm{PH}_{3}$ (Manna et al., 2013), P(SiMe $)_{3}$ (Liu et al., 2016), and P4 (Bichat et al., 2004a).

and alleviate interfacial defects, which is resulted from lattice mismatch in core/shell NCs.

In this review, a representative introduction on the physical properties of metal phosphide NCs is given firstly. Selecting suitable precursor plays an important role in the chemical synthesis of NCs. Different from the synthesis of metal chalcogenide, much more phosphorus precursors have been tested with the purpose of improving the quality, and reducing the production cost of metal phosphide NCs. We give a detail discussion regarding the underlying chemical mechanism on the phosphorus chemistry in the synthesis of metal phosphide NCs. As one key example of metal phosphide, strategies to obtain high quality InP NCs and their core/shell system with $\mathrm{ZnS}$ and ZnSe as passivating shells are summarized. A passivizing shell is of critical importance for InP NCs, because their surfaces are prone to be easily oxidized. We also conclude by pointing out challenges to be addressed in future research, such as broad emission, shape control, and doping of InP NCs. Next, II$\mathrm{V}$ metal phosphide NCs (e.g., $\mathrm{Cd}_{3} \mathrm{P}_{2}, \mathrm{Zn}_{3} \mathrm{P}_{2}$ ) and transition metal phosphides (e.g., copper phosphide, iron phosphide) are presented. Finally, an overview of state-of-the-art applications 
with metal phosphide NCs is provided, such as light-emitting devices (LEDs), photovoltaic cells, and biomedical applications.

\section{PHOSPHORUS PRECURSORS IN COLLOIDAL SYNTHESIS OF INP NANOCRYSTALS}

As the most important metal phosphide, InP has attracted intensive attention. (Green and O'Brien, 1998; Jun et al., 2006; Ung et al., 2008; Zan and Ren, 2012; Bang et al., 2017; Friedfeld et al., 2017). The direct band gap of $1.35 \mathrm{eV}$, high fraction of covalent bonding and the large Bohr exciton radius of $9.6 \mathrm{~nm}$ make the InP NCs an excellent candidate as visible and nearIR emitting materials. The first liquid colloidal synthesis of InP NCs with narrow size distribution was realized by Nozik in 1994 by using $\mathrm{P}\left(\mathrm{SiMe}_{3}\right)_{3}$ (Micic et al., 1994). The P-Si bond in the compound of $\mathrm{P}\left(\mathrm{SiMe}_{3}\right)_{3}$ exhibits relatively low dissociation energy (around $363 \mathrm{~kJ} \mathrm{~mol}^{-1}$ ), which leads to its high reactivity in the case of reacting with an indium precursor. Besides, the phosphorus atom bonded to the highly electropositive $\mathrm{Si}$ atom imparts the necessary driving force to react with indium precursors. Therefore, the resulting InP NCs show wellcrystallized zinc blende structure and modest exciton peak attributed to InP, which is the first time to show an exciton peak for an III-V NC. This strategy was also applied to the synthesis of other binary and ternary III-V QDs, e.g., GaP. GaInP 2 (Micic et al., 1995). Since this pioneering report, $\mathrm{P}\left(\mathrm{SiMe}_{3}\right)_{3}$ has become the most widely used phosphorus precursor in the colloidal synthesis of metal phosphide NCs. Then, utilizing $\mathrm{P}\left(\mathrm{SiMe}_{3}\right)_{3}$ precursor, Micic et al. treated the NCs with a solution of HF or $\mathrm{NH}_{4} \mathrm{~F}$, resulting in highly efficient band-edge emission (Micic et al., 1996, 1997).

In view of their highly reactivity, $\mathrm{P}\left(\mathrm{SiMe}_{3}\right)_{3}$ will be consumed in a few seconds. In this context, the growth of NCs tends to proceed via the Ostwald ripening mechanism, which widens the size distribution (Clark et al., 2011). Furthermore, due to pyrophoric nature, high cost, and hazardous reagents of $\mathrm{P}\left(\mathrm{SiMe}_{3}\right)_{3}$ and secondary products involved in production, several alternatives for $\mathrm{P}\left(\mathrm{SiMe}_{3}\right)_{3}$ are already studied (Reiss et al., 2016). Up to now, following the first synthesis of InP NCs, a variety of phosphorus precursors have been investigated with the main purpose of improving the size distribution. A diversity of phosphorus precursors in the synthesis of InP NCs is summarized in Table $\mathbf{1}$.

Similar to $\mathrm{P}\left(\mathrm{SiMe}_{3}\right)_{3}$ precursor, single-source precursor is a highly reactive precursor, which can shorten the reaction time and avoid the formation of side products, such as of $\operatorname{In}_{2} \mathrm{O}_{3}$. Mark et al. reported the synthesis of high quality InP NCs by using the single source precursor of $\left(\operatorname{In}\left(\mathrm{PBu}_{2}^{\mathrm{t}}\right)_{3}\right)$ (Green and O'Brien, 1998). It is noted that the preparation and storage of such a highly reactive precursor requires great cautions. To address these issues, Li et al. synthesized high quality InP NCs by using the in situ generated $\mathrm{PH}_{3}$ gas as the phosphorus precursor (Li et al., 2008; Zan and Ren, 2012). $\mathrm{PH}_{3}$ is a more stable and safer phosphorus precursor, compared to pyrophoric $\mathrm{P}\left(\mathrm{SiMe}_{3}\right)_{3}$ precursor. Furthermore, the method based on $\mathrm{PH}_{3}$ gas gives access to larger sized InP NCs. In 2008, Reiss et al. reported the synthesis of InP NCs using an elemental P precursor (red $\mathrm{P}$ allotropes) as the phosphorus precursor. To stimulate the reaction, $\mathrm{NaBH}_{4}$ was introduced as the reducing agent. The reaction could proceed with a very high reaction yield approaching 100\% (Ung et al., 2008). Park et al. reported the synthesis of highly luminescent InP/ZnS NCs using an elemental $\mathrm{P}$ precursor of $\mathrm{P}_{4}$ (white $\mathrm{P}$ ) (Bang et al., 2017). They demonstrated that the direct reaction of $\mathrm{P}_{4}$ precursor with In precursor without reducing agent. The sublimation of red $\mathrm{P}$ powder can simply produce $\mathrm{P}_{4}$, therefore $\mathrm{P}_{4}$ precursor represents an additional low-cost $\mathrm{P}$ precursor and provides an important way to the large-scale synthesis on InP NCs.

In order to avoid the rapid depletion of $\mathrm{P}\left(\mathrm{SiMe}_{3}\right)_{3}$, phosphorus precursors with decreased precursor reactivity have been synthesized. Different strategies have been implemented, such as replacing the $\mathrm{Si}$ with Ge or Sn (Harris and Bawendi, 2012), substituting methyl group with butyl or aryl group (Joung et al., 2012; Gary et al., 2014). Replacing Si in the Si-P bond with Ge or Sn reduces the reactivity of the precursor by decreasing the polarity of the bond. Likewise, altering the methyl groups to sterically hindering moieties can reduce the reactivity as well. It is believed that using less reactive precursor is helpful to segregate the nucleation and growth and is essential to reach InP NCs with narrow size distribution. Despite great efforts, these alternatives exhibited either largely unchanged or very slowed conversions compared with $\mathrm{P}\left(\mathrm{SiMe}_{3}\right)_{3}$.

Aminophosphine presents an alternative phosphorus precursor with advantages of low cost, high stability, decent reactivity, and easy handling (Xie et al., 2007; Laufersky et al., 2018; Mundy et al., 2018). Song and coworkers reported for the first time of high-quality InP NCs using $\mathrm{P}\left(\mathrm{NMe}_{2}\right)_{3}$ as a phosphorus precursor (Song et al., 2013). The synthesis was performed by rapid injection of $\mathrm{P}\left(\mathrm{NMe}_{2}\right)_{3}$ into the $\mathrm{InCl}_{3}$ and $\mathrm{ZnCl}_{2}$ solution with oleylamine at $220^{\circ} \mathrm{C}$. They found that the size and size distributions of InP NCs are depended on the amount of $\mathrm{P}\left(\mathrm{NMe}_{2}\right)_{3}, \mathrm{ZnCl}_{2}$ as well as the growth temperature and time. The presence of $\mathrm{ZnCl}_{2}$ in the synthesis plays a role in activating the aminophosphine to undergo a disproportionation reaction and form $\mathrm{P}^{3-}$, which is helpful to achieve narrow size distribution (Laufersky et al., 2018).

Later, Tessier presented an investigation into the chemical reactions of InP formation with $\mathrm{InCl}_{3}$ and aminophosphine precursors (Tessier et al., 2016). Using NMR spectroscopy and single crystal X-ray diffraction and mass spectrometry, they demonstrated that the InP formation underwent $4 \mathrm{P}(+\mathrm{III})$ $\rightarrow \mathrm{P}(-\mathrm{III})+3 \mathrm{P}(+\mathrm{V})$ disproportionation reaction. Since aminophosphines are $\mathrm{P}(\mathrm{III})$ compounds, reduction steps are needed to form InP with an In (III) precursor. As shown in Scheme 1A, an exchange between primary amines and amino groups of phosphorus precursor occurs, indicating that apart from acting as solvent or ligand, primary amines also play an important role in the whole precursor chemistry. Then, 1 equiv of InP is formed by oxidating 3 equiv of the substituted aminophosphine to a phosphonium salt (Scheme 1B). Namely, substituted aminophosphine has a double role in the reaction, both phosphorus precursor and reducing agent. Based on double 
TABLE 1 | Summary of phosphorus precursors in colloidal synthesis of InP NCs.

\begin{tabular}{|c|c|c|c|c|c|}
\hline & P precursors & $\begin{array}{l}\text { In } \\
\text { precursors }\end{array}$ & Methods & Results & References \\
\hline 1998 & $\ln \left(\mathrm{PBu}_{2}^{t}\right)_{3}$ & & $\begin{array}{l}\text { Decomposition of } \\
\ln \left(\mathrm{PBu}_{2}^{t}\right)_{3}\end{array}$ & Quantum confinement effects & Green and O'Brien, 1998 \\
\hline 2006 & $\mathrm{Na}_{3} \mathrm{P}$ & $\mathrm{InCl}_{3}$ & Heat-up & Spherical NCs with $5 \mathrm{~nm}$ & Jun et al., 2006 \\
\hline 2008 & $\mathrm{P}_{4}$ & $\mathrm{InCl}_{3}$ & Hot-injection & Cubic structure with $3-4 \mathrm{~nm}$ & Ung et al., 2008 \\
\hline 2008 & $\mathrm{PCl}_{3}$ & $\ln (\mathrm{Ac})_{3}$ & Heat-up & $\begin{array}{l}\text { Size tunability; HF-etching improved the } \\
\text { quantum yield (QY) }\end{array}$ & Liu et al., 2008 \\
\hline $\begin{array}{l}2008 \\
2012\end{array}$ & $\mathrm{PH}_{3}$ & $\ln (A c)_{3}$ & $\begin{array}{l}\text { Gas-liquid phase } \\
\text { synthesis }\end{array}$ & InP/ZnS NCs: QY of 30-60\% & $\begin{array}{l}\text { Li et al., 2008; Zan and Ren, } \\
2012\end{array}$ \\
\hline 2012 & $\mathrm{P}\left(\mathrm{SiMe}_{2} \text {-tert-Bu}\right)_{3}$ & $\ln (\mathrm{Ac})_{3}$ & Hot-injection & $\begin{array}{l}\text { Large size of InP NCs: } \\
\text { InP/ZnS NCs: QY of } 18-28 \%\end{array}$ & Joung et al., 2012 \\
\hline 2012 & $\mathrm{P}\left(\mathrm{GeMe}_{3}\right)_{3}$ & $\ln (M A)_{3}$ & Hot-injection & Improved size distribution & Harris and Bawendi, 2012 \\
\hline 2013 & $\mathrm{P}\left(\mathrm{NMe}_{2}\right)_{3}$ & $\mathrm{InCl}_{3}$ & Hot-injection & $\begin{array}{l}\text { Size tunability; InP/ZnS NCs: emission } \\
\text { FWHM:60-64 nm; QY: 51-53\% }\end{array}$ & Song et al., 2013 \\
\hline 2013 & TOP & $\begin{array}{l}\left.\operatorname{lnCl}\right|_{3}, \operatorname{lnF}_{3} \\
\operatorname{lnBr}_{3}\end{array}$ & Hot-injection & Size tunability & Lauth et al., 2013 \\
\hline 2014 & $\mathrm{P}\left(\mathrm{SiPh}_{3}\right)_{3}, \mathrm{P}\left(\mathrm{SiMe}_{3}\right)_{3}$ & $\ln (\mathrm{MA})_{3}$ & Hot-injection & Separated the nucleation and growth & Gary et al., 2014 \\
\hline 2015 & $\begin{array}{l}\text { Single-source precursors: InP } \\
\text { MA MSCs from } \mathrm{P}\left(\mathrm{SiMe}_{3}\right)_{3} \text { and } \\
\ln (\mathrm{MA})_{3}\end{array}$ & & Hot-injection & $\begin{array}{l}\text { Conversion of InP MSCs to NCs } \\
\text { proceeded via a supersaturated solution }\end{array}$ & Gary et al., 2015 \\
\hline 2015 & $\mathrm{P}\left(\mathrm{NEt}_{2}\right)_{3}$ & $\mathrm{InCl}_{3}, \operatorname{lnI}_{3}, \operatorname{lnBr}_{3}$ & Hot-injection & $\begin{array}{l}\text { InP/ZnS NCs: emission FWHM of } \\
\text { 46-63 nm; QY: 50-60\% }\end{array}$ & Tessier et al., 2015 \\
\hline 2017 & $\mathrm{P}\left(\mathrm{SiMe}_{3}\right)_{3}$ & $\ln (A c)_{3}$ & Heat-up & $\begin{array}{l}\text { Zn-P intermediate complex lowered the } \\
\text { reactivity of } \mathrm{P}\left(\mathrm{SiMe}_{3}\right)_{3}\end{array}$ & Koh et al., 2017 \\
\hline 2017 & $\mathrm{P}_{4}$ & $\operatorname{lnCl}_{3}, \ln _{3}$ & Hot-injection & $\begin{array}{l}\text { Large-scale production; InP/ZnS NCs: } \\
\text { emission FWHM: 50-80 nm; QY: 60\% }\end{array}$ & Bang et al., 2017 \\
\hline
\end{tabular}

role of phosphorus, this mechanism assumes a nucleophilic attack by the phosphorus center of one aminophosphine on an amino group of another aminophosphine. Firstly, $\mathrm{InCl}_{3}$ reacts with $\mathrm{P}(\mathrm{NHR})_{3}$ to form adducts with different resonance structures (Scheme 1B-I), thus, the positive charge can delocalize over the phosphorus center and the nitrogen atoms, making it possible for residual $\mathrm{P}(\mathrm{NHR})_{3}$ to nucleophilic attack nitrogen atoms, as showed in Scheme 1B-II. Subsequent phosphorus nucleophilic substitution results in InP unit formation. This mechanism explains why full conversion of the In precursor is only attained for a $4: 1 \mathrm{P} / \mathrm{In}$ ratio.

Since then, InP NCs with aminophosphine precursors have been further investigated: utilizing the precursors, the resulting green NCs achieved comparable PL performance to previous work with $\mathrm{P}\left(\mathrm{SiMe}_{3}\right)_{3}$ (PLQY: 82 vs. 85\%) (Jang et al., 2018). Tetrahedrally shaped InP NCs with improved stability ascribed to oleylamine and chloride ligands (Kim et al., 2016). Zinc salts were also found to activate the aminophosphine precursors by accelerating the formation of the In-P(I) pseudomonomer. Moreover, admixing Cd into a ZnSe shell could also be valid in synthesizing strain-free NCs, suppressing self-absorption, and reducing the amount of NCs for application (Dupont et al., 2017; Rafipoor et al., 2018). Cossairt et al. also demonstrated that aminophosphines were versatile precursors for metal phosphide NCs beyond InP (Mundy et al., 2018).

In short, InP NCs synthesized with aminophosphine precursor, have competitive properties to those from $\mathrm{P}\left(\mathrm{SiMe}_{3}\right)_{3}$ routes, indicating that aminophosphine is a promising option for the synthesis of InP NCs. Recently, mechanism of reaction and surface states has been confirmed by X-ray absorption spectroscopy, Raman scattering measurements, and NMR Spectroscopy, etc. (Janke et al., 2018; Laufersky et al., 2018; Tessier et al., 2018). These progresses indicate that synthesis of high quality and efficient InP NCs with the low cost, high stability, decent reactivity, and easy handling precursor will enable to obtain InP NCs on a large scale for a variety of applications, and lead to the extension of colloidal synthesis toward other pnictide NCs.

\section{INDIUM PHOSPHIDE NANOCRYSTALS}

InP quantum emitting materials have been considered as an alternative substitution to the conventional quantum dots (QDs), with advantages of less toxicity. Technically speaking, the heavy metal of $\mathrm{Cd}$ or $\mathrm{Pb}$ in quantum dots-based electronics devices will cause minor environment issue because of the very low concentrations. These heavy metal issues can be further reduced to an even low level by appropriate encapsulation technique and recycling policy after disposal. However, the introduction of heavy-metal materials in electrical and electronic equipment has been restricted the regulation released by Restriction of Hazardous Substances Directive in the EU. Therefore, many researchers have shifted the interests from $\mathrm{Cd}$ or $\mathrm{Pb}$ based NCs to Cd-free alternatives, i.e., InP QDs. 


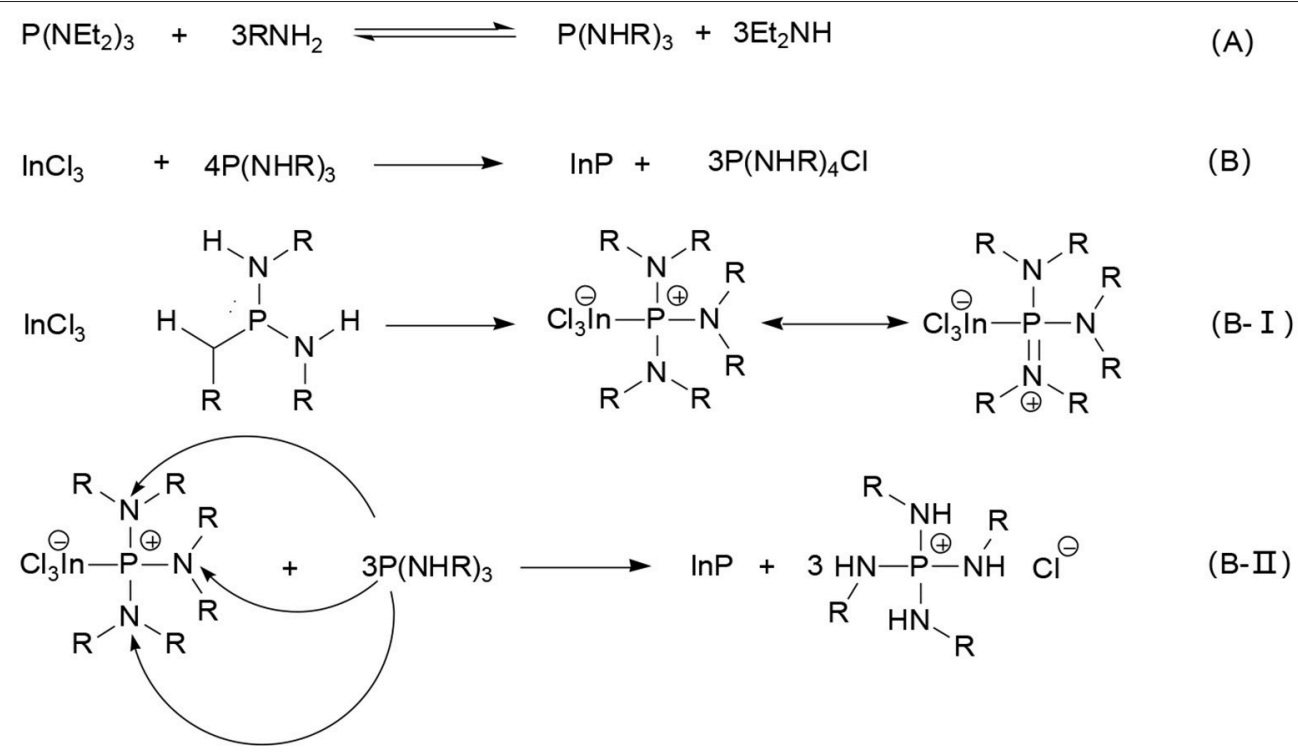

SCHEME 1 | Mechanism of reaction of $\mathrm{P}\left(\mathrm{NEt}_{2}\right)_{3}$ with $\operatorname{InP} \mathrm{NCs}(\mathbf{A})$. P(NEt $)_{3}$ first reacts with the primary amine to obtain $\mathrm{P}(\mathrm{NHR})_{3}$, then $\mathbf{( B )} 1$ equiv of InP is formed by oxidating 3 equiv of the substituted aminophosphine to a phosphonium salt. Namely, (B-1) after the synthesis of In-P complex, (B-II) $P$ nucleophilic substitution reaction, finally $\mathrm{InP}$ unit is obtained. Reproduced with permission from Tessier et al. (2016). (c) 2016 American Chemical Society.

Indeed, toxicological evaluation reveals that InP QDs display minor toxicity and decent bio-compatibility, thereby suggesting that they can be utilized for potential bio-imaging applications. For instance, Lin et al. found that no observable toxicity in vivo after intravenous injection of InP/ZnS QDs in mice for 84 days (Lin et al., 2015). Brunetti et al. studied the toxicity of CdSe/ZnS and InP/ZnS QDs in vitro as well as for in vivo applications (Brunetti et al., 2013). CdSe/ZnS QDs were shown to induce cell membrane damage, interference with $\mathrm{Ca}^{2+}$ homeostasis, which ascribed to the presence of $\mathrm{Cd}^{2+}$, while InP/ZnS QDs exhibited low toxicity. Chibli et al. showed that the cytotoxicity induced by the generation of reactive oxygen species was shown to be significantly lower in the case of InP/ZnS QDs as compared to CdTe/ZnS QDs (Chibli et al., 2011). Taken together, toxicity studies demonstrate that these InP based QDs constitute a less toxic alternative to Cd based QDs. All these toxicity evaluations support that the InP QDs pose less environment concerns and guarantee the commercialization of InP QDs based electronics devices.

At the early stages, InP NCs were characterized as low PLQY, poor photo-stability, in particular its wide PL linewidth, in contrast to Cd-based NCs. In the following decades, the synthesis of InP NCs has achieved progress toward the improvements on the PLQY, PL stability, and narrowing the PL linewidth. Figure 2 shows optical absorption, PL spectra, and TEM images of different NCs. The highest QY in literature for InP QDs was reported above $80 \%$, which is close to unity PLQY of CdSe QDs and cesium lead halide perovskites $\left(\mathrm{CsPb}_{3}\right) \mathrm{NCs}$ (Zhang et al., 2013; Nedelcu et al., 2015). Coating InP NCs with a shell can afford improved photostability, which allows for many applications. However, the wide PL linewidth limits their applications where narrow emission is required, i.e., multiple-color displays. The narrowest PL linewidth, estimated as full-width at half maximum (fwhm), for InP-based core/shell or alloy NCs is $35 \mathrm{~nm}$ at $488 \mathrm{~nm}$ (Figure 2A) (Ramasamy et al., 2017), which is still inferior to CdSe QDs and CsPbX 3 QDs.

In fact, intrinsic emission line width of InP NCs is comparable to CdSe NCs (Figure 3A-IV) (Cui et al., 2013), suggesting that the emission of InP NCs is heterogeneously broadened due to size distribution. The very broad size distribution of InP NCs indicates that separating nucleation and growth is difficult to achieve (Tamang et al., 2016), due to the more covalent nature of the III-V precursors and the fast depletion of precursors at high temperature (Allen et al., 2010).

Several methods have been used to improve size tunability and size distribution, including employing zinc chloride as reaction additive, and replacing $\mathrm{P}\left(\mathrm{SiMe}_{3}\right)_{3}$ with lower cost, toxicity, and higher stability phosphorus precursors. Effects of $\mathrm{Zn}$ species in InP NC synthesis include the reduction of surface defects, facilitation of subsequent shell growth, and improvement of size distribution (Yang et al., 2012). The use of aminophosphine precursors $\left(\mathrm{P}\left(\mathrm{NMe}_{2}\right)_{3}\right.$ and $\left(\mathrm{P}\left(\mathrm{NEt}_{2}\right)_{3}\right)$ enable the preparation of InP NCs with state-of-the-art quality in the literature.

Increasing core growth time also results in broadened size distribution of InP NCs. Hens et al. expanded this approach by replacing $\mathrm{P}\left(\mathrm{NMe}_{2}\right)_{3}$ with $\mathrm{P}\left(\mathrm{NEt}_{2}\right)_{3}$, attaining a close to full yield conversion of indium precursor, and demonstrating size tuning was possible by changing the indium halide salt (Tessier et al., 2015). Changing of the precursor concentration is a size-tuning strategy, i.e., higher concentrations lead to smaller NCs, whereas decreasing the concentration appears to deteriorate the size distribution. Inspired by changing the free ligand concentration or the ligand chain length with CdSe NCs (Abe et al., 2013). Tessier and coworkers changed the indium salt halide. When all other reaction conditions were kept constant, 

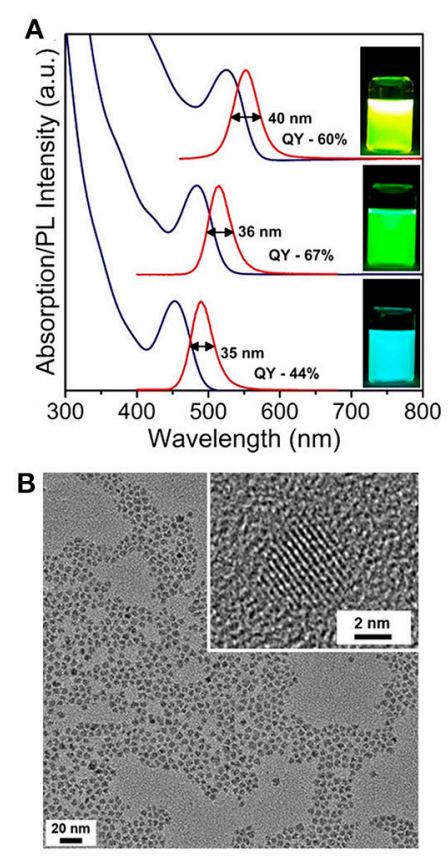

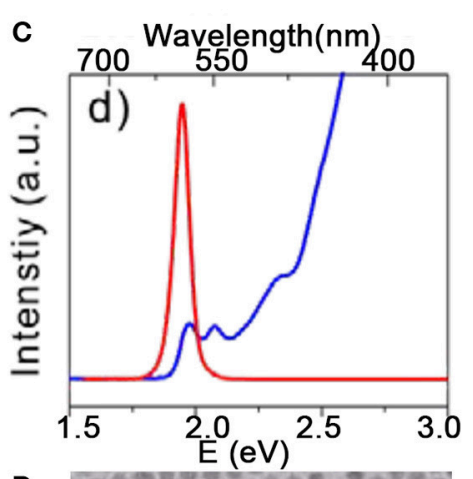

D

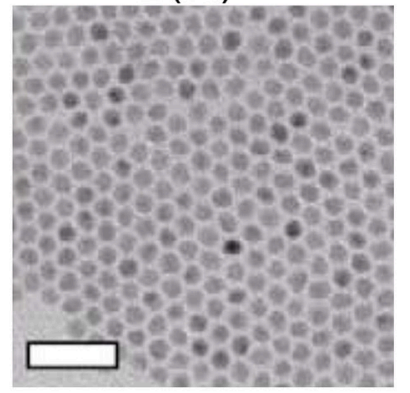

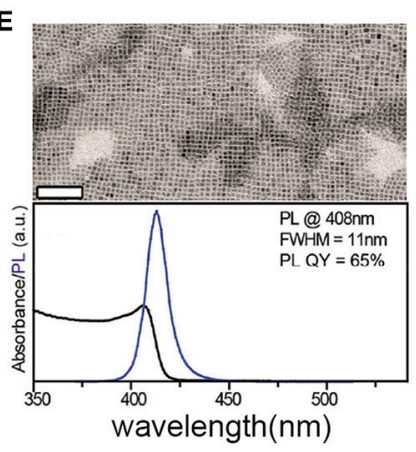

$\mathbf{F}$

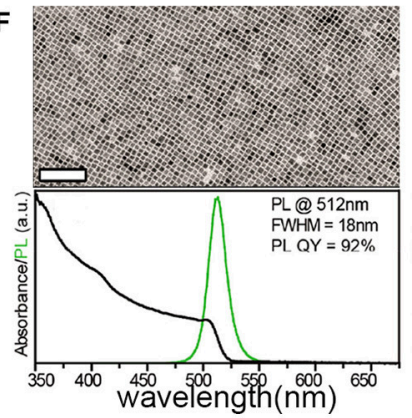

FIGURE 2 | (A) In(Zn)P/ZnSe/ZnS NCs emitting at 488, 516, and $552 \mathrm{~nm}$ have fwhm of 35, 36, and $40 \mathrm{~nm}$. (B) $535 \mathrm{~nm}$ emitting In(Zn)P/ZnSe/ZnS NCs with the size of $4.2 \mathrm{~nm}$. Reproduced with permission from Ramasamy et al. (2017). ๑ 2017 American Chemical Society. (C,D) Absorption, PL spectra, and TEM images of CdSe/CdS NCs with CdSe core diameters of $5.4 \mathrm{~nm}$ and CdS shell thickness of $2.3 \mathrm{~nm}$. Reproduced with permission from Chen et al. (2013) ๑ 2013 Springer Nature. Scale bars are $50 \mathrm{~nm}$. TEM images, absorption, and PL spectra of (E) $\mathrm{CsPbCl}_{3}$, (F) $\mathrm{CsPbBr}_{3}$ NCs. Reproduced with permission from Imran et al. (2018). (0 2018 American Chemical Society. Scale bars are $100 \mathrm{~nm}$. https://pubs.acs.org/doi/10.1021/jacs.7b13477. Notice:further permissions related to the material excerpted should be directed to the ACS.

the first exciton position can be tuned from 570 to 550 or $520 \mathrm{~nm}$ by replacing $\mathrm{InCl}_{3}$ by $\mathrm{InBr}_{3}$ or $\mathrm{InI}_{3}$, respectively, allowing for an efficient size tuning by changing of the indium halide precursor.

Up to now, the narrowest emission of ensemble InP NCs were reported to be ca. $40 \mathrm{~nm}$ (Ramasamy et al., 2018), which is still wider than the line widths of PL acquired at the single particle level, suggesting that colloidal synthesis gave rise to the intrinsic inhomogeneity in InP NCs, that was previously attributed to broadened size distribution. Interestingly, recent report reveals that the broad emission may be caused by surface states and lattice disorder, that was confirmed by utilizing X-ray absorption spectroscopy and Raman scattering measurements (Janke et al., 2018). These findings suggest that developing new colloidal synthesis with the purpose of decreasing surface and lattice defects will be the future challenges to achieve comparable performance to CdSe NCs. Furthermore, dopant ions within lattice of NCs were found to be as important as control of the surface states to obtain bright dopant emission ( $\mathrm{Pu}$ et al., 2017). $\mathrm{Ag}^{+}$dopants can be introduced into lattice of CdSe NCs precisely (Sahu et al., 2012), while few works exist on the doped InP NCs. Recent reports demonstrate that $\mathrm{Ag}$ and $\mathrm{Cu}$ are of interest as doping agents for dual-emissive InP NCs, therefore, the NCs have potential applications in biological and LEDs applications (Zhang et al., 2015; Yang et al., 2017; Vinokurov et al., 2018). In conclusion, synthetic development specifically for these applications is an interesting avenue to explore.
So far, quite limited progress has been achieved in shape control of InP NCs, only tetrahedral (Kim et al., 2016) and spherical NCs are reported. Colloidal nanoplatelets differ from NCs due to the strong quantum confinement acting in one dimension, which have been most extensively studied. CdSe nanoplatelets can be synthesized with a thickness controlled with monolayer precision, gaining access to a wide spectral range (Christodoulou et al., 2018). Hence, as for InP, development of such $2 \mathrm{D}$ heterostructures can be a promising and exciting future direction.

\section{INDIUM PHOSPHIDE-BASED CORE/SHELL NANOCRYSTALS}

The concept of core/shell in NCs has been widely implemented for the conventional CdSe based core/shell structures. Coating an additional shell around the initial seeds provides extra means to manipulate their properties. The obvious benefit is allowing one to easily obtain NCs with enhanced fluorescence efficiency and improved stability against photo-oxidation. This is of particularly importance for the InP NCs, because even freshly synthesized colloidal InP NCs exhibit PLQY of $<1 \%$ due to surface defects related to $\mathrm{P}$ atoms. Talapin et al. found that treating InP NCs with HF can reconstruct the surface and enhance the PLQY up to $40 \%$ (Adam et al., 2005). Besides, InP NCs without protecting shell are prone to surface oxidation and photodegradation. Therefore, 


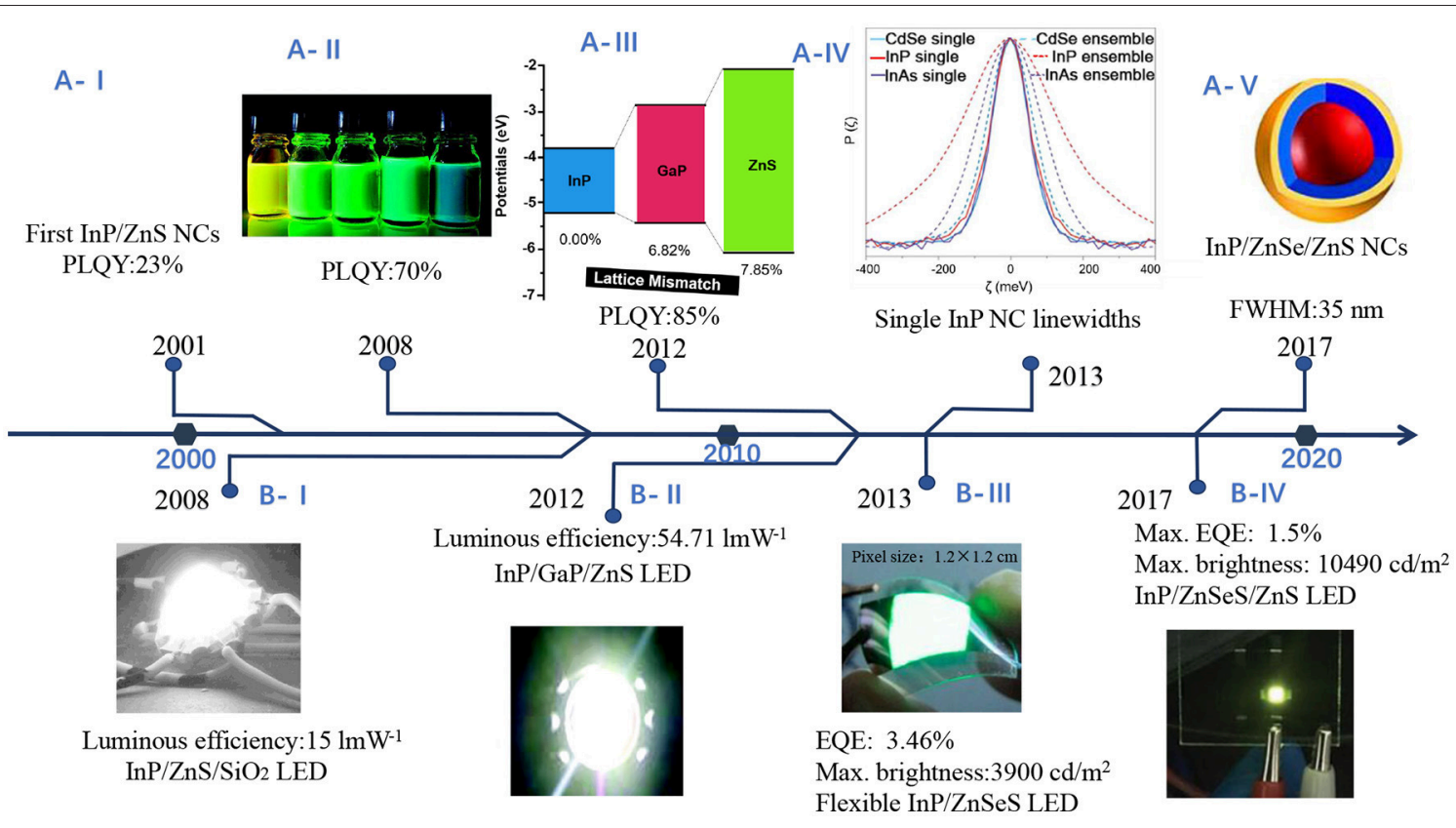

FIGURE 3 | Research timeline illustrating (A) improvements on luminescence performance (B) progress toward to various applications of InP NCs in light-emitting diodes. (A-I) InP/ZnS NCs with PLQY of 23\% (Haubold et al., 2001) (A-II). Highly luminescent InP/ZnS NCs. Reproduced with permission from Li and Reiss (2008). ๑ 2008 American Chemical Society. (A-III) InP/GaP/ZnS NCs with a maximum PLQY of 85\%. Reproduced with permission from Kim et al. (2012) ๑) 2012 American Chemical Society. (A-IV) Single InP NC linewidths. Reproduced with permission from Cui et al. (2013) ๑ 2013 Springer Nature. (A-V) In(Zn)P/ZnSe/ZnS NCs with emission fwhm as narrow as $35 \mathrm{~nm}$. Reproduced with permission from Ramasamy et al. (2017). () 2017 American Chemical Society. (B-I) InP/ZnS NCs as converter material in white LEDs. Reproduced with permission from Ziegler et al. (2008) with permission of John Wiley and Sons. (B-II) White LEDs with InP/GaP/ZnS NCs. Reproduced with permission from Kim et al. (2012). () 2012 American Chemical Society. (B-III) LEDs with InP/ZnSeS. Reproduced with permission from Lim et al. (2013). ๑ 2013 American Chemical Society. (B-IV) LEDs with InP/ZnSeS/ZnS. Reproduced with permission from Wang et al. (2017) with permission of John Wiley and Sons.

coating InP with a passivating shell is the prerequisite for further their applications.

Most importantly, band gap offsets and lattice strain between core and shell significantly modify the intraband and interband states, and affect the carrier dynamics of exciton (Dupont et al., 2017; Rafipoor et al., 2018). Therefore, it is possible to prepare the core/shell QDs with unusual and practical photophysical properties. Brainis found that a thick $\mathrm{ZnSe}$ shell coating is helpful to reach nearly non-blinking NCs (Chandrasekaran et al., 2017). Hollingsworth et al. reported that coating InP NCs with 11 monolayers of CdS can significantly increase the biexciton lifetime up to $7 \mathrm{~ns}$, indicating dramatic suppression of nonradiative Auger recombination (Dennis et al., 2012). So far, $\mathrm{ZnSe}$ and $\mathrm{ZnS}$ are often used as shell materials for the obvious reason of their large band gap and low toxicity. Herein, we will summarize recent progress toward the synthesis of InP based core/shell direction.

The first issue encountered in the synthesis of core/shell structured $\mathrm{InP} / \mathrm{ZnSe}$ and $\mathrm{InP} / \mathrm{ZnS} \mathrm{NCs}$ is the relatively large lattices mismatch. In case of former is $3.3 \%$, and in the latter is approaching to $7.7 \%$. The epitaxial growth of shell on top of InP NCs has been proved to be challenging, due to the large lattice constant $(\mathrm{a}=5.93 \AA$ ). Besides, defects may exist due to the strain at the core/shell interfaces induced by lattice mismatch. Therefore, finding appropriate strategies to avoid defect formation represents one of the main challenges in the synthesis of InP based core/shell NCs.

Overcoating the NCs with a shell of ZnS leads to high PLQY, as shown in Figure 3A. Haubold et al. first passivated the InP core with $\mathrm{ZnS}$, enhanced the PLQY to 23\% (Figure 3A-I) (Haubold et al., 2001). They used diethylzinc and bis(trimethylsilyl) sulfide to grow $\mathrm{ZnS}$ on $\mathrm{InP} \mathrm{NCs}$ at $260^{\circ} \mathrm{C}$ for a limited time, aiming to avoid Ostwald ripening. TEM images and XPS data indicated the formation of $\mathrm{ZnS}$ passivated InP NCs. Then one-pot synthesis without precursor injection gave access to InP/ZnS NCs with a maximum PLQY of 70\% (Figure 3A-II), narrow emission line width (40-60 $\mathrm{nm}$ fwhm) and excellent photostability ( $\mathrm{Li}$ and Reiss, 2008). The high PLQY is likely attributed to the "smooth" core/shell interface with few defect states. So far, the highest PLQY (85\%) (Figure 3A-III) has been reported for the InP/GaP/ZnS NCs with superior photostability as compared to InP/ZnS NCs (Kim et al., 2012), where $\mathrm{In}^{3+}$ ions are effectively replaced by $\mathrm{Ga}^{3+}$ ions near the surface. The intermediate layer $\mathrm{GaP}$ mitigates the effect of lattice mismatch between InP and $\mathrm{ZnS}$. Lattice strain with a $\mathrm{ZnS}$ shell may limit a shell thickness $<1 \mathrm{~nm}$, making NCs vulnerable against degradable conditions. To alleviate lattice strain, Lee et al. used $\mathrm{ZnSe}$ as a lattice adaptor to achieve thicker shells $(1.9 \mathrm{~nm})$, the NCs exhibited high PLQY, and enhanced stability under UV irradiation, ligand exchange or rigorous purification (Lim et al., 2011). 
Pietra et al. found that $\operatorname{In}_{\mathrm{x}} \mathrm{Zn}_{\mathrm{y}} \mathrm{P}$ alloy NCs with a tunable lattice constant can be prepared by changing the amount of zinc precursor, which can match a chosen shell material, possibly creating strain-free core/shell NCs (Pietra et al., 2016). As a result, PLQY of InZnP/ZnSeS NCs can reach as high as $60 \%$. Optical spectra, PLQY and TEM images of $\operatorname{In}_{\mathrm{X}} \mathrm{Zn}_{\mathrm{y}} \mathrm{P}$ NCs are shown in Figures 4A-C. They also found that a preferential Ga-for-Zn cation exchange leaded to a InZnP/InGaP core/shell system with increased PLQY when $\mathrm{Zn} / \mathrm{In} \geq 0.5$. Another $\mathrm{GaP}$ and $\mathrm{ZnSeS}$ outer shell of InZnP/InGaP NCs exhibit enhanced PLQY (over 70\%) and stability (Pietra et al., 2017). Structure and optical spectra of InZnP/InGaP/GaP/ZnSeS NCs are shown in Figures 4D-F.

\section{COLLOIDAL SYNTHESIS OF II-V METAL PHOSPHIDE NANOCRYSTALS}

Cadmium phosphide has been the subject of intensive interest owing to its unique physical properties. $\mathrm{Cd}_{2} \mathrm{P}_{3}$ is a narrow bandgap semiconductor $(0.55 \mathrm{eV}$ in bulk) with high dielectric constant (5.8), large Bohr exciton radius $(36 \mathrm{~nm})$. All these features suggest that $\mathrm{Cd}_{2} \mathrm{P}_{3}$ in quantum-dot form presents a new material with emission wavelengths span the visible through the near-infrared.

Miao et al. for the first time, reported the colloidal synthesis of cadmium phosphide $\mathrm{NCs}$ using $\mathrm{P}\left(\mathrm{SiMe}_{3}\right)_{3}$ as a phosphorus precursor in the presence of oleylamine and trioctylphosphine as ligands (Miao et al., 2010). By varying the temperature and growth time, they obtained high quality $\mathrm{Cd}_{3} \mathrm{P}_{2} \mathrm{NCs}$ with tunable emission ranging from 650 to $1,200 \mathrm{~nm}$, and with high PLQY up to ca. $40 \%$. Further research from the same group found that replacing $\mathrm{P}\left(\mathrm{SiMe}_{3}\right)_{3}$ by $\mathrm{PH}_{3}$ will reach cadmium phosphide NCs with different stoichiometric $\left(\mathrm{Cd}_{6} \mathrm{P}_{7}\right.$ instead of $\left.\mathrm{Cd}_{3} \mathrm{P}_{2},\right)$ and improved size distribution (Miao et al., 2012). Figure 5A shows the absorption spectra with multiple transition of Cd6P7 $\mathrm{NCs}$ for the first time. TEM images in Figure 5B show that $\mathrm{Cd}_{6} \mathrm{P}_{7}$ NCs are monodisperse with nearly spherical shape, and the average size of NCs is $6.5 \pm 0.3 \mathrm{~nm}$. Since $\mathrm{PH}_{3}$ is less reactive compared to $\mathrm{P}\left(\mathrm{SiMe}_{3}\right)_{3}$, size of NCs is well controlled by the low reaction rate. This simple and inexpensive strategy paves the way to large-scale production of metal phosphide NCs.

Xie et al. reported an advanced synthesis of $\mathrm{Cd}_{3} \mathrm{P}_{2} \mathrm{NCs}$ using $\mathrm{P}\left(\mathrm{SiMe}_{3}\right)_{3}$ as a phosphorus precursor and using oleic acid as the only ligand (Xie et al., 2010). They found that under these conditions, the size of the obtained NCs can be tuned in in the range of $1.6-12 \mathrm{~nm}$ by simply adjusting the concentration of the oleic acid. Figure 5C shows PL spectra of $\mathrm{Cd}_{3} \mathrm{P}_{2} \mathrm{NCs}$ with various sizes, which covers the whole visible and near-IR (450 to over $1,500 \mathrm{~nm}$ ) region. The optical properties make the NCs useful in optical amplification and lighting. TEM images of $\mathrm{Cd}_{3} \mathrm{P}_{2} \mathrm{NCs}$ with $12 \mathrm{~nm}$ are given in Figure 5D, where a square array of the NCs is observed.

Cadmium phosphide NCs in the absence of protecting shell can be easily oxidized, which hinders their application in open air. Delpech reported a method for the coating of cadmium phosphide NCs (Ojo et al., 2012). The coating procedure was performed by using zinc acetate and ethylene sulfide as the zinc and sulfur precursors, respectively. They obtained high-quality $\mathrm{Cd}_{3} \mathrm{P}_{2} / \mathrm{ZnS}$ NCs with PLQY over $50 \%$ with modest air stability.

Zinc phosphide $\left(\mathrm{Zn}_{3} \mathrm{P}_{2}\right)$ has great potential as a solar absorber in thin film photovoltaics, because of its high absorption coefficient in the order of $10^{-4}-10^{-5} \mathrm{~cm}^{-1}$, large carries diffusion length of 5-10 $\mu \mathrm{m}$, mostly importantly suitable band gap of $1.5 \mathrm{eV}$ (Green and O'Brien, 2001). The band gap of $\mathrm{Zn}_{3} \mathrm{P}_{2}$ is very close that of CdTe and slightly narrower than CdSe, indicating its high solar absorption capability. Fabrication of $\mathrm{Zn}_{3} \mathrm{P}_{2}$ in the quantum size has been intensively pursued for a long time, because $\mathrm{Zn}_{3} \mathrm{P}_{2}$ NCs can potentially be an emitting material like CdTe and CdSe NCs (Luber et al., 2013). Besides, $\mathrm{Zn}_{3} \mathrm{P}_{2}$ exhibits superior features in contrast to CdTe, CdSe, and InP, because both the $\mathrm{Zn}$ and the $\mathrm{P}$ are nontoxic and earth abundant elements.

Up to now, there have been several reports on the synthesis of $\mathrm{Zn}_{3} \mathrm{P}_{2}$ NCs. The reported synthetic approaches of colloidal $\mathrm{Zn}_{3} \mathrm{P}_{2}$ NCs borrow experiences from the synthesis of other metal phosphide NCs, utilizing the same phosphorus precursor, such as $\mathrm{P}_{4}, \mathrm{TOP}, \mathrm{PH}_{3}$, and $\mathrm{P}\left(\mathrm{SiMe}_{3}\right)_{3}$ and the same ligands such as TOP. The zinc precursor includes dimethylzinc, diethylzinc, and zinc stearate. It is worth noting that the formation of $\mathrm{Zn}_{3} \mathrm{P}_{2}$ compounds in liquid solution is difficult compared with other metal phosphides. For instance, significant quantity of $\mathrm{ZnCl}_{2}$ is often used, during the synthesis of InP NCs. However, Extensive analysis suggests that under the conditions of the InP synthesis, zincs are not incorporated into the core of the final InP NCs. This feature explains the reason that early reports on the synthesis of NCs usually give poor crystalline and low $\mathrm{PL}$ product. This is also consistent with many observations that the synthesis of $\mathrm{Zn}_{3} \mathrm{P}_{2} \mathrm{NCs}$ requires much higher temperatures.

Green reported the first colloidal synthesis of $\mathrm{Zn}_{3} \mathrm{P}_{2} \mathrm{NCs}$ displaying quantum confined emission (Green and O'Brien, 2001). The synthesis was performed by using dimethylzinc as zinc precursor and the primary phosphine $\mathrm{H}_{2} \mathrm{P}^{t} \mathrm{Bu}$ as phosphorus source. The obtained particles were revealed as a mixture of both crystalline and amorphous materials. Miao et al. reported the synthesis of $\mathrm{Zn}_{3} \mathrm{P}_{2} \mathrm{NCs}$ by using either gas $\mathrm{PH}_{3}$ or $\mathrm{P}\left(\mathrm{SiMe}_{3}\right)_{3}$ as phosphorus precursor and diethylzinc or zinc stearate as the zinc source (Miao et al., 2013) Buriak and coworkers synthesized monodisperse and pure crystalline $\mathrm{Zn}_{3} \mathrm{P}_{2} \mathrm{NCs}$ at low temperature (Mobarok et al., 2014). From the selected area electron diffraction (SAED) pattern in Figure 5E and XRD spectrum, these NCs were found to possess the crystalline tetragonal $\alpha-\mathrm{Zn}_{3} \mathrm{P}_{2}$ structure. TEM image in Figure $5 \mathbf{F}$ shows the average size of NCs is $14.7 \pm 2.1 \mathrm{~nm}$, with a distribution of $14 \%$. In general, to date the reported synthesis of $\mathrm{Zn}_{3} \mathrm{P}_{2} \mathrm{NCs}$ is more limited than cadmium and indium based NCs, mostly likely due to the large differences in reactivity between traditional zinc and cadmium precursors with conventional pnictide sources. Literature on colloidal $\mathrm{Zn}_{3} \mathrm{P}_{2} \mathrm{NCs}$ mainly focuses on designing the synthesis and understanding the structure and properties of the NCs instead of their practical device application. 

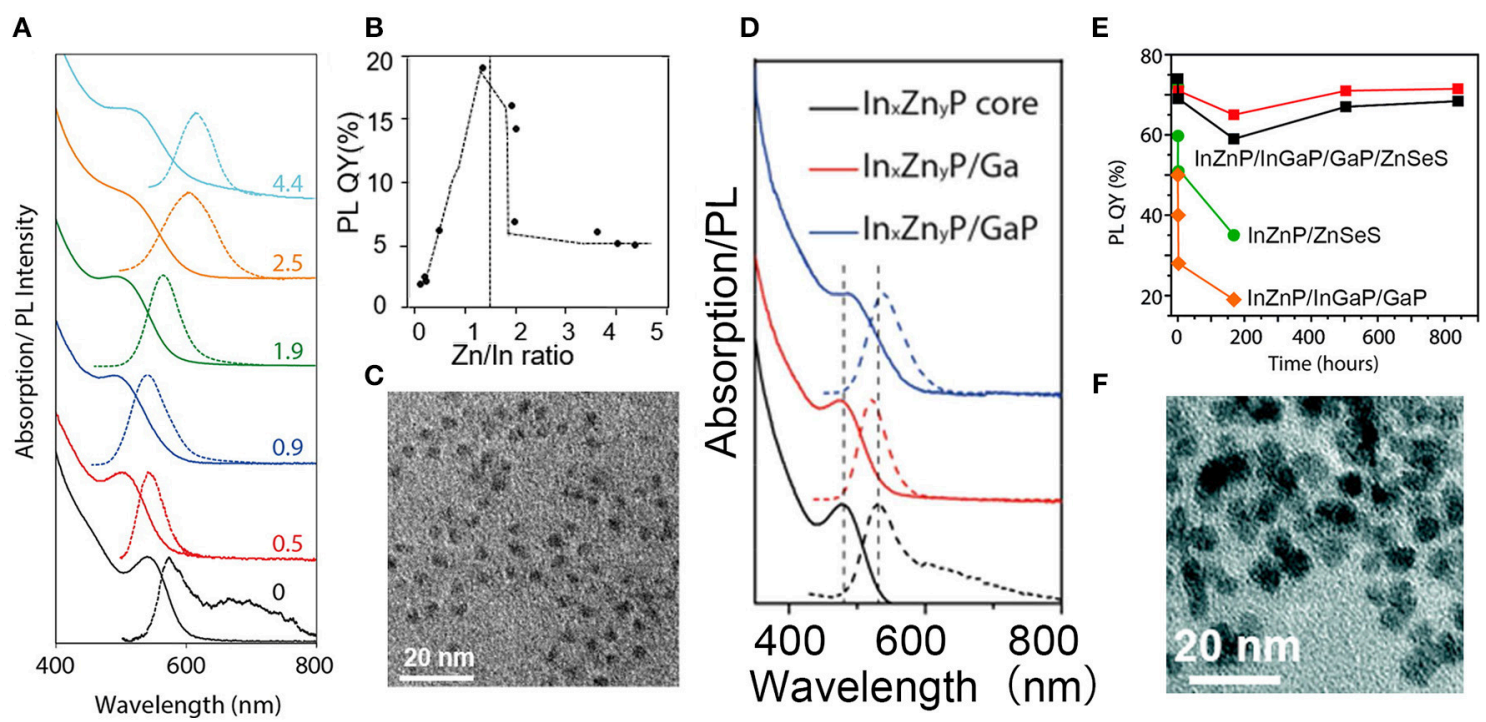

$\mathbf{F}$

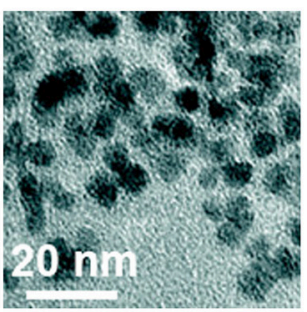

FIGURE 4 | (A) Absorption and PL spectra of $I n_{x} Z n_{y} P$ NCs. (B) PLQY of $I n_{x} Z n_{y} P$ NCs obtained by Inductively Coupled Plasma (ICP) Optical Emission Spectroscopy (OES) elemental analysis. (C) TEM image of $\operatorname{In}_{x} Z n_{y} P / Z n S e_{z} S_{1-z}$ core/shell NCs. Reproduced with permission from Pietra et al. (2016). ๑ 2016 American Chemical Society. (D) Absorption and emission spectra of InZnP NCs (Zn/ln = 1.5). (E) PLQYs for four suspensions of NCs. Four samples were measured: two batches of purified InZnP/InGaP/GaP/ZnSeS NCs (red and black squares), InZnP/ZnSeS NCs (green dots), and InZnP/lnGaP/GaP NCs (orange diamonds). (F) TEM images of InZnP/InGaP/GaP/ZnSeS NCs. Reproduced with permission from Pietra et al. (2017). ๑ 2017 American Chemical Society. https://pubs.acs.org/doi/abs/10.1021/acs. chemmater.7b00848. Notice:further permissions related to the material excerpted should be directed to the ACS.

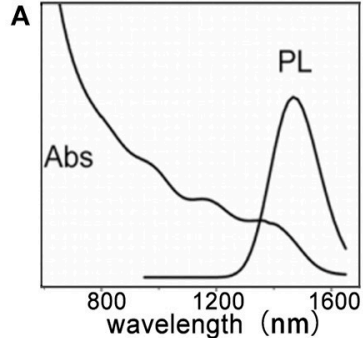

B

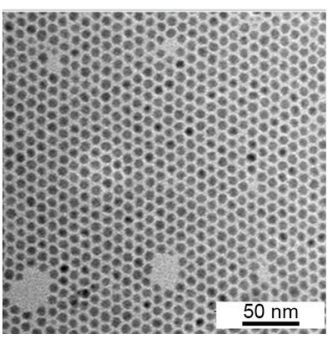

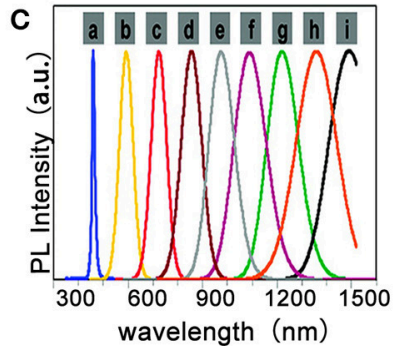

D

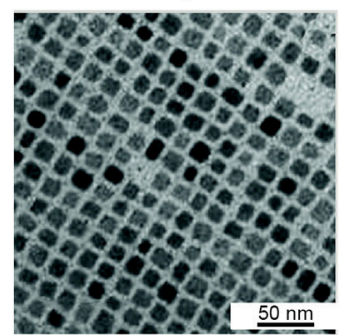

$\mathbf{E}$

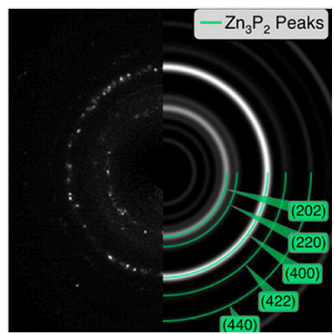

$\mathbf{F}$

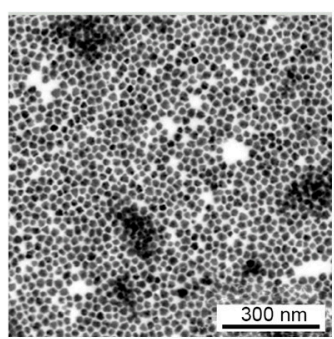

FIGURE 5 | (A,B) $\mathrm{Cd}_{6} \mathrm{P}_{7}$ NCs synthesized at $250^{\circ} \mathrm{C}$ with 40 min growth-time. Reproduced with permission from Miao et al. (2012). (๑ 2012 American Chemical Society. (A) Absorption and PL spectra of $\mathrm{Cd}_{6} \mathrm{P}_{7}$ NCs. (B) TEM images show high quality of $\mathrm{Cd}_{6} \mathrm{P}_{7} \mathrm{NCs}$. (C,D) $\mathrm{Cd}_{3} \mathrm{P}_{2} \mathrm{NCs}$ prepared at $250^{\circ} \mathrm{C}$ with $\left.\mathrm{P}(\mathrm{SiMe})_{3}\right)_{3}$

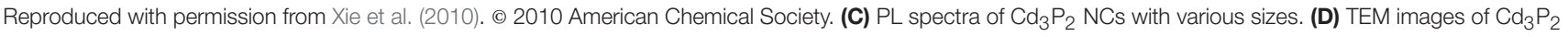
NCs with $12 \mathrm{~nm}(\mathbf{E}, \mathbf{F}) . \mathrm{Zn}_{3} \mathrm{P}_{2}$ NCs synthesized with $\mathrm{P}\left(\mathrm{SiMe}_{3}\right)_{3}$ for $1 \mathrm{~h}$. Reproduced with permission from Mobarok et al. (2014). ( 2014 American Chemical Society. (E) SAED pattern and simulation of $\alpha-Z n_{3} P_{2}$ ring pattern. (F) TEM of $Z n_{3} P_{2}$ NCs.

\section{COLLOIDAL SYNTHESIS OF TRANSITION METAL PHOSPHIDE NANOCRYSTALS}

Recently, transition metal phosphide NCs have attracted intense interest for their potential in catalysis, magnetic recording media, and as anode materials in lithium ion batteries (Bichat et al., 2004b; Brock and Senevirathne, 2008). Among these, iron phosphides exist in a wide range of stoichiometry, their properties depend on their physical and electronic structures, such as $\mathrm{Fe}_{3} \mathrm{P}$ and $\mathrm{Fe}_{2} \mathrm{P}$ are ferromagnetic, $\mathrm{FeP}$ is super magnetic, 
$\mathrm{FeP}_{2}$ and $\mathrm{FeP}_{4}$ are antimagnetic semiconductors (Blanchard et al., 2008). $\mathrm{Cu}_{3} \mathrm{P}$ NCs are air-stable and environmentally friendly materials. When they are used in batteries, their theoretical weight capacitances are slightly higher than that of graphite, and volumetric capacities are more than three times greater than that of graphite (Bichat et al., 2004a).

Nowadays, TOP is often used as a phosphorus precursor in the synthesis of transition metal phosphide NCs. Schaak et al. reported the colloidal synthesis of $\mathrm{Cu}_{3} \mathrm{P}$ NCs for the first time, by injecting the $\mathrm{Cu}$ NCs and TOP into the TOPO at high temperature (Henkes and Schaak, 2007). It is found that metals can cause cleavage of the $\mathrm{P}-\mathrm{C}$ bond, resulting in diffusion of phosphorus into the metal. Falqui et al. optimized the synthesis by replacing $\mathrm{Cu}$ NCs with cuprous chloride $(\mathrm{CuCl})$ to react with TOP, and obtained $\mathrm{Cu}_{3} \mathrm{P}$ NCs with improved size distributions (De Trizio et al., 2012). The ratio of TOP and $\mathrm{CuCl}$ determined $\mathrm{Cu}_{3} \mathrm{P}$ NCs either by a direct formation of $\mathrm{Cu}_{3} \mathrm{P}$ nucleation or by forming $\mathrm{Cu} \mathrm{NCs}$ first and then converting into $\mathrm{Cu}_{3} \mathrm{P}$ NCs. The former way leads to reproducible and size controllable pure $\mathrm{Cu}_{3} \mathrm{P}$, while the latter way results in the formation of $\mathrm{Cu}$ $\mathrm{Cu}_{3} \mathrm{P}$ Janus-like NCs, which is unsuitable for applications in batteries with larger copper domains. Manna et al. reported the synthesis of by using $\mathrm{PH}_{3}$ as the $\mathrm{P}$ precursor (Manna et al., 2013). The synthesis can be performed under relatively lower reaction temperature. The obtained $\mathrm{Cu}_{3} \mathrm{P}$ nanoplatelets was found to be single crystalline and possess the semiconducting, plasmonic, and rectification properties. More recently, Liu et al. used the more active $\mathrm{P}\left(\mathrm{SiMe}_{3}\right)_{3}$ as the $\mathrm{P}$ precursor and prepared the $\mathrm{Cu}_{3-\mathrm{x}} \mathrm{P}$ NCs at very low reaction temperature (Liu et al., 2016). They further demonstrated that the localized surface plasmon resonance and nonlinear optical absorption of the $\mathrm{Cu}_{3-\mathrm{x}} \mathrm{P} \mathrm{NCs}$ can be modulated by thermal treatment.

Perera et al. firstly reported the synthesis of iron phosphides $\mathrm{NCs}$ by reaction of $\mathrm{Fe}(\mathrm{acac})_{3}$ with $\mathrm{P}\left(\mathrm{SiMe}_{3}\right)_{3}$ in TOPO at $260^{\circ} \mathrm{C}$, resulting product in pure $\mathrm{FeP}$ phase, round shape, narrow size distribution, and high colloidal stability (Perera et al., 2003; Brock and Senevirathne, 2008). Park and coworkers synthesized uniform-sized $\mathrm{FeP}$ and $\mathrm{Fe}_{2} \mathrm{P}$ nanorods from thermal decomposition of iron-phosphine complexes (Park et al., 2005). Schaak et al. reported the synthesis of FeP NCs by using pre-synthesized Fe NCs to react with TOP in hexadecylamine (Henkes and Schaak, 2007). Recently, Liu et al. used inexpensive and air-stable triphenyl phosphite (Figure 6A) as the phosphorus sources and prepared rod-shaped $\mathrm{Fe}_{2} \mathrm{P}$ NCs (Liu et al., 2018). Figure 6 displays representative TEM images of the $5 \pm 1 \mathrm{~nm}$ $\times 22 \pm 5 \mathrm{~nm}$ rod-shaped $\mathrm{Fe}_{2} \mathrm{P}$ nanoparticles (Figures 6B,C), $4.5 \pm 1 \mathrm{~nm} \times 17 \pm 1 \mathrm{~nm}$ disk-shaped $\mathrm{Cu}_{3} \mathrm{P}$ nanoparticles (Figures 6E,F).

\section{APPLICATION}

Colloidal NCs are covered by a layer of ligands, which can stabilize the colloidal NCs in suitable solvents. This unique feature enables the fabrication of thin film electronic devices by well-established coating and printing techniques. In view of great progress toward the synthesis by means of inexpensive and scalable, wet-chemical synthetic procedures, colloidal QDs are emerging as a versatile class material in electronic devices, in contrast to expensive physically manufacturing processes. Besides, colloidal NCs open up new opportunities to integrate inorganic semiconductors devices with advanced features such as high-performance, large-area, and flexibility.

Among them, colloidal metal phosphide NCs offer a powerful platform for solution-processable electronic and optoelectronic devices, including photodetectors (Keuleyan et al., 2011), photovoltaic cells and light-emission devices (Steckel et al., 2003; Li et al., 2008; Qian et al., 2011), as shown in Figure 7. The actual active element in electronic and optoelectronic devices is macroscopic array of NCs (Talapin et al., 2010), which act as the key components with functions of light absorption or emission and charge transportation (Gaponenko et al., 2016; Kagan et al., 2016). Figure 3B shows progress toward to various applications of InP NCs in LEDs.

Commercialization of conventional quantum dots-based lighting emitting diodes are facing the strict regulation on the using of hazardous substances, such as $\mathrm{Cd}$ and $\mathrm{Pb}$. Recent progress toward the synthesis of high-quality InP QDs provides a solution to address this issue. InP QDs have been widely applied in white lighting emitting devices as down conversion phosphor (Ziegler et al., 2008; Yang et al., 2012) and in the framework of electroluminescence devices (Lim et al., 2013; Shen et al., 2017; Wang et al., 2017; Ramasamy et al., 2018). Lim et al. reported design of InP QDs based electroluminescence light emitting diodes (Lim et al., 2013). The device structure based on InP QDs is shown in Figure 7A. By optimizing the charge balance, they observed direct formation of exciton within QDs and efficient radiative exciton recombination. The external quantum efficiency is reported as $3.46 \%$ and brightness is $3,900 \mathrm{~cd} \mathrm{~m}^{-2}$. In a recent report, the brightness was improved to $10,000 \mathrm{~cd} \mathrm{~m}^{-2}$ by using $\mathrm{ZnMgO}$ as the electron transporting layer to improve the electron injection (Wang et al., 2017). The effect of Auger recombination, Förster resonant energy transfer among the closely packed QDs in a thin film of QLEDs, have a negative effect on device efficiency of QLED. Thus, thick shells or interfacial alloy layer acting as an effective spacer can suppress the above effects. A record of external quantum efficiency of $6.6 \%$ in heavy-metal-free red QLEDs have been achieved with a thick $\mathrm{ZnS}$ shell of InP/ZnSe/ZnS QDs (15 nm) (Cao et al., 2018). That means there is still more room for improvement and optimization. Moreover, replacing red, green, blue (RGB) color filters with narrow-band green, red InP/ZnSeS/ZnS QD films in color-by-blue QD-emissive liquid-crystal displays (LCDs) results in 1.49 times greater in the relative luminance levels, 2.42 times higher in EQE values than conventional color filter (CF)-LCD, making it possible to replace conventional RGB CF-assisted LCDs (Kang et al., 2018).

$\mathrm{Cd}_{3} \mathrm{P}_{2}$ NCs and $\mathrm{Zn}_{3} \mathrm{P}_{2}$ NCs have been considered as promising materials for photovoltaic applications. Cao et al. proposed $\mathrm{PbS} / \mathrm{Cd}_{3} \mathrm{P}_{2}$ quantum heterojunction for $\mathrm{NC}$ photovoltaic cells, where $\mathrm{p}$ - and n-layers were quantum-tunable and solution-processed infrared light absorbers (Cao et al., 2015). The increased thickness of an n-layer type $\mathrm{Cd}_{3} \mathrm{P}_{2}$ from 


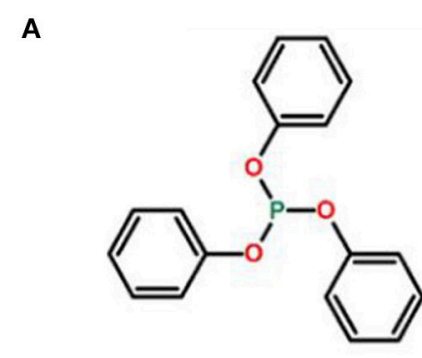

B

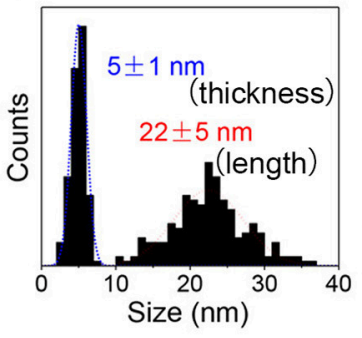

D

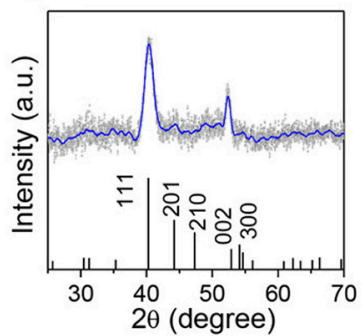

C

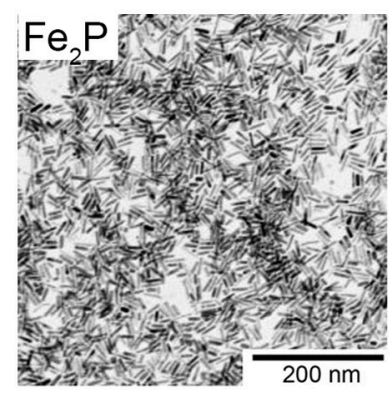

$\mathbf{F}$

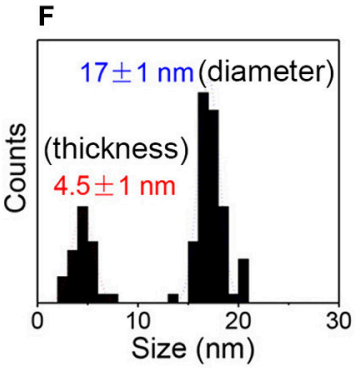

E $\mathrm{Cu}_{3} \mathrm{P}$

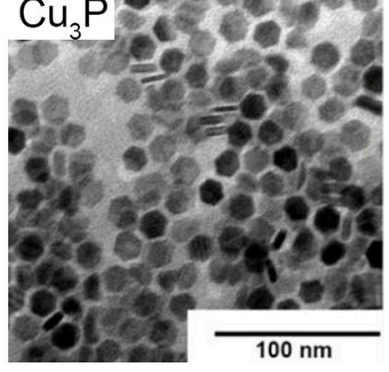

G

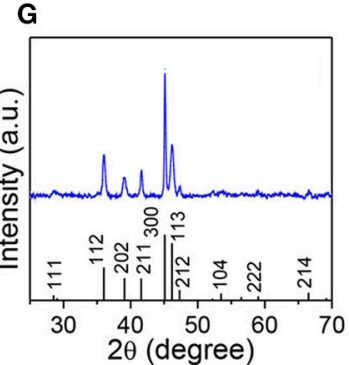

FIGURE 6 | (A) Chemical structure of triphenyl phosphite. (B,C) TEM images and nanorod length and thickness distribution histograms of Fe 2 P. nanoparticles (D) XRD pattern of $\mathrm{Fe}_{2} \mathrm{P}$ nanoparticles. The reference JCPDS pattern of $\mathrm{Fe}_{2} \mathrm{P}$ (01-076-089) is also included in the XRD graph. (E,F) TEM images and disk diameter and thickness distribution histograms of $\mathrm{Cu}_{3} \mathrm{P}$ nanoparticles $\mathbf{( G )} X R D$ pattern of $\mathrm{Cu}_{3} \mathrm{P}$ nanoparticles. The reference JCPDS pattern of Cu $3 \mathrm{P}(01-071-2261)$ is also included in the XRD graph. Reproduced with permission from Liu et al. (2018). (c) 2018 American Chemical Society.

A light-emitting diode

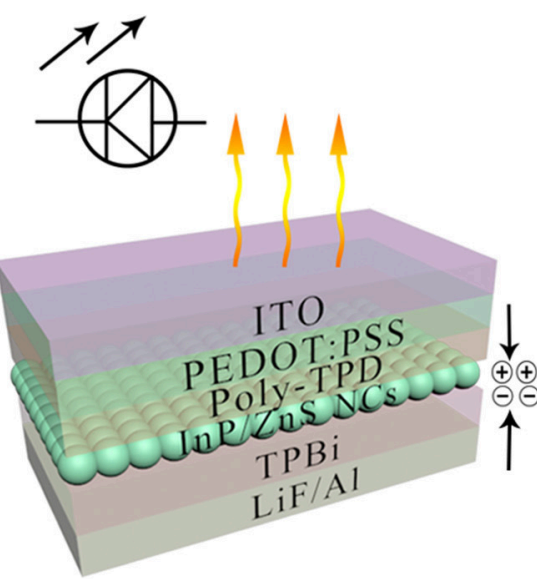

B phototransistor
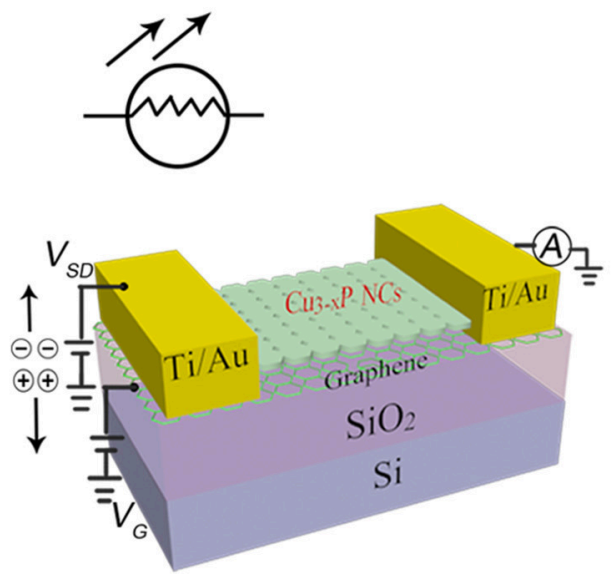

FIGURE 7 | Colloidal nanocrystal device architectures with metal phosphide NCs. (A) A white-LED using InP/ZnS NCs. Reproduced with permission from Yang et al. (2012) with permission of John Wiley and Sons. (B) Phototransistors based on the hybrid graphene-Cu $3-x$ P NC structure. Reproduced with permission from Sun et al. (2017) with permission of John Wiley and Sons.

one layer to two layers resulted in devices exhibiting a power conversion of $1.5 \%$, with an open-circuit voltage of $0.39 \mathrm{~V}$, a short-circuit current of $8.4 \mathrm{~mA} \mathrm{~cm}-2$ and a fill factor of $45 \%$. Luber and coworkers tested photovoltaic performance of heterojunction devices consisting of ITO/ZnO/Zn ${ }_{3} \mathrm{P}_{2} / \mathrm{MoO}_{3} / \mathrm{Ag}$ (Luber et al., 2013). The device possessed excellent rectification behavior (rectification ratio of 600) and photosensitivity (on/off ratio of $\sim 10^{2}$ under $100 \mathrm{~mW} \mathrm{~cm}^{-2} \mathrm{AM} 1.5 \mathrm{G}$ illumination). Charge carrier mobilities and lifetimes for InP and InZnP QDs are comparable to those of PbS QDs after an $\left(\mathrm{NH}_{4}\right)_{2} \mathrm{~S}$ ligand-exchange procedure, making it possible to utilize $\operatorname{In}(\mathrm{Zn}) \mathrm{P}$ QD films in solar cells. Power conversion efficiencies of 0.65 and $1.2 \%$ were achieved of the solar cells based on InP and InZnP QDs, respectively (Crisp et al., 2018). 
Recently, Sun demonstrated high-performance, broadband photodetectors with the hybrid graphene- $\mathrm{Cu}_{3-\mathrm{x}} \mathrm{P}$ NC structure (Sun et al., 2017). The efficient three-terminal photodetectors (phototransistors) (Figure 7B) exhibit photoresponse from 400 to $1,550 \mathrm{~nm}$ with an ultrahigh responsivity $\left(1.59 \times 10^{5} \mathrm{~A} \mathrm{~W}^{-1}\right)$ and high photoconductive gain $\left(6.66 \times 10^{5}\right)$ at $405 \mathrm{~nm}$, and a good responsivity of $9.34 \mathrm{~A} \mathrm{~W}^{-1}$ at $1,550 \mathrm{~nm}$. The light-activated functionality of device is provided by a layer of strongly lightabsorbing colloidal NCs and an ultrafast carrier transportation graphene layer.

In summary, the prospect of employing metal phosphide NCs in optoelectronic devices offers a number of unique benefits related to their photo-physical properties. Therefore, the colloidal synthesis of various types of metal phosphide NCs has been steadily increasing in recent years and further stimulates their applications. Among them, InP, $\mathrm{Cd}_{3} \mathrm{P}_{3}$, and $\mathrm{Zn}_{3} \mathrm{P}_{2} \mathrm{NCs}$ are of significant importance in many light absorption and emission-based applications, such as photovoltaics and light emitting diodes. Particularly, InP and $\mathrm{Zn}_{3} \mathrm{P}_{3}$ are of great interest due to their suitable band gap and low intrinsic toxicity. Despite excellent properties, they are still facing critical issues before they can replace conventional NCs. Compared to chalcogenide-based NCs, metal phosphide NCs exhibit

\section{REFERENCES}

Abe, S., Capek, R. K., De Geyter, B., and Hens, Z. (2013). Reaction chemistry/nanocrystal property relations in the hot injection synthesis, the role of the solute solubility. ACS Nano 7, 943-949. doi: 10.1021/nn30 59168

Adam, S., Talapin, D. V., Borchert, H., Lobo, A., McGinley, C., de Castro, A. R. B., et al. (2005). The effect of nanocrystal surface structure on the luminescence properties: photoemission study of HF-etched InP nanocrystals. J. Chem. Phys. 123:084706. doi: 10.1063/1.2004901

Allen, P. M., Walker, B. J., and Bawendi, M. G. (2010). Mechanistic insights into the formation of InP quantum dots. Angew. Chem. Int. Edn. 49, 760-762. doi: 10.1002/anie.200905632

Bang, E., Choi, Y., Cho, J., Suh, Y. H., Ban, H. W., Son, J. S., et al. (2017). Large-scale synthesis of highly luminescent InP@ZnS quantum dots using elemental phosphorus precursor. Chem. Mater. 29, 4236-4243. doi: 10.1021/acs.chemmater.7b00254

Bichat, M. P., Politova, T., Pascal, J. L., Favier, F., and Monconduit, L. (2004a). Electrochemical reactivity of Cu3P with lithium. J. Electrochem. Soc. 151, A2074-A2081. doi: 10.1149/1. 1815156

Bichat, M. P., Politova, T., Pfeiffer, H., Tancret, F., Monconduit, L., Pascal, J. L., et al. (2004b). Cu3P as anode material for lithium ion battery: powder morphology and electrochemical performances. J. Power Sources 136, 80-87. doi: 10.1016/j.jpowsour.2004.05.024

Blanchard, P. E. R., Grosvenor, A. P., Cavell, R. G., and Mar, A. (2008). X-ray photoelectron and absorption spectroscopy of metal-rich phosphides M2P and M3P (M = Cr-Ni). Chem. Mater. 20, 7081-7088. doi: $10.1021 / \mathrm{cm} 80$ $2123 \mathrm{a}$

Brock, S. L., and Senevirathne, K. (2008). Recent developments in synthetic approaches to transition metal phosphide nanoparticles for magnetic and catalytic applications. J. Solid State Chem. 181, 1552-1559. doi: 10.1016/j.jssc.2008.03.012

Brunetti, V., Chibli, H., Fiammengo, R., Galeone, A., Malvindi, M. A., Vecchio, G., et al. (2013). InP/ZnS as a safer alternative to $\mathrm{CdSe} / \mathrm{ZnS}$ core/shell quantum dots: in vitro and in vivo toxicity assessment. Nanoscale 5, 307-317. doi: $10.1039 / \mathrm{C} 2 \mathrm{NR} 33024 \mathrm{E}$ synthetically induced broad size distributions, and low PLQYs and poor thermo- and photo-stability stability. Significant attention has been given to improving these aspects, from viewpoint of chemistry. However, additional attention must be paid to the optimization of their photo-physical properties via structure engineering at the interface and controlling the exciton dynamics. Currently, the performance of optoelectronic devices based on metal phosphide NCs is largely limited due to the undeveloped synthetic methods. Future development of the synthetic approach for metal phosphide NCs is expected to lead to the high-performance optoelectronic devices, i.e., displays.

\section{AUTHOR CONTRIBUTIONS}

All authors listed have made a substantial, direct and intellectual contribution to the work, and approved it for publication.

\section{ACKNOWLEDGMENTS}

We gratefully appreciate the financial support from the National Natural Science Foundation of China (21701015 and 21811530054).

Cao, F., Wang, S., Wang, F. J., Wu, Q. Q., Zhao, D. W., and Yang, X. Y. (2018). A layer-by-layer growth strategy for large-size InP/ZnSe/ZnS core-shell quantum dots enabling high-efficiency light-emitting diodes. Chem. Mater. 30, 8002-8007. doi: 10.1021/acs.chemmater.8b03671

Cao, H. F., Liu, Z. K., Zhu, X. X., Peng, J., Hu, L., Xu, S. M., et al. (2015). PbS/Cd3P2 quantum heterojunction colloidal quantum dot solar cells. Nanotechnology 26:035401. doi: 10.1088/0957-4484/26/3/035401

Carenco, S., Demange, M., Shi, J., Boissiere, C., Sanchez, C., Le Floch, P., et al. (2010). White phosphorus and metal nanoparticles: a versatile route to metal phosphide nanoparticles. Chem. Commun. 46, 5578-5580. doi: $10.1039 / \mathrm{c} 0 \mathrm{cc} 00684 \mathrm{j}$

Carenco, S., Portehault, D., Boissiere, C., Mezailles, N., and Sanchez, C. (2013). Nanoscaled metal borides and phosphides: recent developments and perspectives. Chem. Rev. 113, 7981-8065. doi: 10.1021/cr400020d

Chandrasekaran, V., Tessier, M. D., Dupont, D., Geiregat, P., Hens, Z., and Brainis, E. (2017). Nearly blinking-free, high-purity single-photon emission by colloidal InP/ZnSe quantum dots. Nano Lett. 17, 6104-6109. doi: 10.1021/acs.nanolett.7b02634

Chen, O., Zhao, J., Chauhan, V. P., Cui, J., Wong, C., Harris, D. K., et al. (2013). Compact high-quality CdSe-CdS core-shell nanocrystals with narrow emission linewidths and suppressed blinking. Nat. Mater. 12, 445-451. doi: $10.1038 /$ nmat3539

Chibli, H., Carlini, L., Park, S., Dimitrijevic, N. M., and Nadeau, J. L. (2011). Cytotoxicity of $\mathrm{InP} / \mathrm{ZnS}$ quantum dots related to reactive oxygen species generation. Nanoscale 3, 2552-2559. doi: 10.1039/c1nr10131e

Christodoulou, S., Climente, J. I., Planelles, J., Brescia, R., Prato, M., Martin-Garcia, B., et al. (2018). Chloride-Induced thickness control in CdSe nanoplatelets. Nano Lett. 18, 6248-6254. doi: 10.1021/acs.nanolett.8b02361

Clark, M. D., Kumar, S. K., Owen, J. S., and Chan, E. M. (2011). Focusing nanocrystal size distributions via production control. Nano Lett. 11, 1976-1980. doi: $10.1021 / \mathrm{nl} 200286 \mathrm{j}$

Coe, S., Woo, W. K., Bawendi, M., and Bulovic, V. (2002). Electroluminescence from single monolayers of nanocrystals in molecular organic devices. Nature 420, 800-803. doi: 10.1038/nature01217

Crisp, R. W., Kirkwood, N., Grimaldi, G., Kinge, S., Siebbeles, L. D. A., and Houtepen, A. J. (2018). Highly photoconductive InP quantum dots films and solar cells. ACS Appl. Energy Mater. 1, 6569-76. doi: 10.1021/acsaem.8b01453 
Cui, J., Beyler, A. P., Marshall, L. F., Chen, O., Harris, D. K., Wanger, D. D., et al. (2013). Direct probe of spectral inhomogeneity reveals synthetic tunability of single-nanocrystal spectral linewidths. Nat. Chem. 5, 602-606. doi: $10.1038 /$ nchem. 1654

Dai, X. L., Zhang, Z. X., Jin, Y. Z., Niu, Y., Cao, H. J., Liang, X. Y., et al. (2014). Solution-processed, high-performance light-emitting diodes based on quantum dots. Nature 515, 96-99. doi: 10.1038/nature13829

De Trizio, L., Figuerola, A., Manna, L., Genovese, A., George, C., Brescia, R., et al. (2012). Size-tunable, hexagonal plate-like $\mathrm{Cu} 3 \mathrm{P}$ and Janus-like $\mathrm{Cu}-\mathrm{Cu} 3 \mathrm{P}$ Nanocrystals. ACS Nano 6, 32-41. doi: 10.1021/nn203702r

Dennis, A. M., Mangum, B. D., Piryatinski, A., Park, Y. S., Hannah, D. C., Casson, J. L., et al. (2012). Suppressed blinking and Auger recombination in nearinfrared type-II InP/CdS nanocrystal quantum dots. Nano Lett. 12, 5545-5551. doi: $10.1021 / \mathrm{nl} 302453 \mathrm{x}$

Dupont, D., Tessier, M. D., Smet, P. F., and Hens, Z. (2017). Indium phosphidebased quantum dots with shell-enhanced absorption for luminescent downconversion. Adv. Mater. 29:1700686. doi: 10.1002/adma.201700686

Friedfeld, M. R., Stein, J. L., and Cossairt, B. M. (2017). Main-group-semiconductor cluster molecules assynthetic intermediates to nanostructures. Inorg. Chem. 56, 8689-8697. doi: 10.1021/acs.inorgchem.7b00291

Gaponenko, S., Demir, H. V., Seassal, C., and Woggon, U. (2016). Colloidal nanophotonics: the emerging technology platform. Optics Express 24, A430A433. doi: 10.1364/OE.24.00A430

Gary, D. C., Glassy, B. A., and Cossairt, B. M. (2014). Investigation of indium phosphide quantum dot nucleation and growth utilizing triarylsilylphosphine precursors. Chem. Mater. 26, 1734-1744. doi: 10.1021/cm500102q

Gary, D. C., Terban, M. W., Billinge, S. J. L., and Cossairt, B. M. (2015). Two-step nucleation and growth of InP quantum dots via magic-sized cluster intermediates. Chem. Mater. 27, 1432-1441. doi: 10.1021/acs.chemmater.5b00286

Green, M., and O'Brien, P. (1998). A novel metalorganic route for the direct and rapid synthesis of monodispersed quantum dots of indium phosphide. Chem. Commun. 22, 2459-2460. doi: 10.1039/a806419i

Green, M., and O'Brien, P. (2001). A novel metalorganic route to nanocrystallites of zinc phosphide. Chem. Mater. 13, 4500-4505. doi: 10.1021/cm011009i

Greenwood, N. N., Parish, R. V., and Thornton, P. (1966). Metal borides. Q. Rev. 20, 441-464. doi: 10.1039/qr9662000441

Harris, D. K., and Bawendi, M. G. (2012). Improved precursor chemistry for the synthesis of III-V quantum dots. J. Am. Chem. Soc. 134, 20211-20213. doi: $10.1021 /$ ja309863n

Haubold, S., Haase, M., Kornowski, A., and Weller, H. (2001). Strongly luminescent InP/ZnS core-shell nanoparticles. Chemphyschem 2, 331-334. doi: 10.1002/1439-7641(20010518)2:5<331::AID-CPHC331>3.0.CO;2-0

Henkes, A. E., and Schaak, R. E. (2007). Trioctylphosphine: a general phosphorus source for the low-temperature conversion of metals into metal phosphides. Chem. Mater. 19, 4234-4242. doi: 10.1021/cm071021w

Ho, M. Q., Esteves, R. J. A., Kedarnath, G., and Arachchige, I. U. (2015). Sizedependent optical properties of luminescent Zn3P2 quantum dots. J. Phys. Chem. C 119, 10576-10584. doi: 10.1021/acs.jpcc.5b01747

Hong, G. S., Antaris, A. L., and Dai, H. J. (2017). Near-infrared fluorophores for biomedical imaging. Nat. Biomed. Eng. 1:0010. doi: 10.1038/s41551-016-0010

Hunger, C., Ojo, W. S., Bauer, S., Xu, S., Zabel, M., Chaudret, B., et al. (2013). Stoichiometry-controlled FeP nanoparticles synthesized from a single source precursor. Chem. Commun. 49, 11788-11790. doi: 10.1039/c3cc46863a

Imran, M., Caligiuri, V., Wang, M. J., Goldoni, L., Prato, M., Krahne, R., et al. (2018). Benzoyl halides as alternative precursors for the colloidal synthesis of lead-based halide perovskite nanocrystals. J. Am. Chem. Soc. 140, 2656-2664. doi: $10.1021 /$ jacs.7b13477

Jang, E. P., Jo, J. H., Lim, S. W., Lim, H. B., Kim, H. J., Han, C. Y., et al. (2018). Unconventional formation of dual-colored InP quantum dot-embedded silica composites for an operation-stable white light-emitting diode. J. Mater. Chem. C 6, 11749-11756. doi: 10.1039/C8TC04095H

Janke, E. M., Williams, N. E., She, C. X., Zherebetskyy, D., Hudson, M. H., Wang, L. L., et al. (2018). Origin of broad emission spectra in InP quantum dots: contributions from structural and electronic disorder. J. Am. Chem. Soc. 140, 15791-15803. doi: 10.1021/jacs.8b08753

Joung, S., Yoon, S., Han, C. S., Kim, Y., and Jeong, S. (2012). Facile synthesis of uniform large-sized InP nanocrystal quantum dots using tris(tert-butyldimethylsilyl)phosphine. Nanoscale Res. Lett. 7:93 doi: 10.1186/1556-276X-7-93

Jun, K. W., Khanna, P. K., Hong, K. B., Baeg, J. O., and Suh, Y. D. (2006). Synthesis of InP nanocrystals from indium chloride and sodium phosphide by solution route. Mater. Chem. Phys. 96, 494-497. doi: 10.1016/j.matchemphys.2005.07.041

Kagan, C. R., Lifshitz, E., Sargent, E. H., and Talapin, D. V. (2016). Building devices from colloidal quantum dots. Science 353:aac5523. doi: 10.1126/science.aac5523

Kang, H., Kim, S., Oh, J. H., Yoon, H. C., Jo, J. H., Yang, H., et al. (2018). Color-by-blue QD-emissive LCD enabled by replacing RGB color filters with narrow-band GR InP/ZnSeS/ZnS QD films. Adv. Optic. Mater. 6:1701239. doi: 10.1002/adom.201701239

Keuleyan, S., Lhuillier, E., Brajuskovic, V., and Guyot-Sionnest, P. (2011). Midinfrared HgTe colloidal quantum dot photodetectors. Nat. Photo. 5, 489-493. doi: 10.1038/nphoton.2011.142

Khanna, P. K., Singh, N., and More, P. (2010). Synthesis and band-gap photoluminescence from cadmium phosphide nano-particles. Curr. Appl. Phys. 10, 84-88. doi: 10.1016/j.cap.2009.05.002

Kim, K., Yoo, D., Choi, H., Tamang, S., Ko, J. H., Kim, S., et al. (2016). Halideamine co-passivated indium phosphide colloidal quantum dots in tetrahedral shape. Angew. Chem. Int. Ed. Engl. 55, 3714-3718. doi: 10.1002/anie.201600289

Kim, S., Kim, T., Kang, M., Kwak, S. K., Yoo, T. W., Park, L. S., et al. (2012). Highly luminescent InP/GaP/ZnS nanocrystals and their application to white lightemitting diodes. J. Am. Chem. Soc. 134, 3804-3809. doi: 10.1021/ja210211z

Koh, S., Eom, T., Kim, W. D., Lee, K., Lee, D., Lee, Y. K., et al. (2017). Zincphosphorus complex working as an atomic valve for colloidal growth of monodisperse indium phosphide quantum dots. Chem. Mater. 29, 6346-6355. doi: 10.1021/acs.chemmater.7b01648

Laufersky, G., Bradley, S., Frecaut, E., Lein, M., and Nann, T. (2018). Unraveling aminophosphine redox mechanisms for glovebox-free InP quantum dot syntheses. Nanoscale 10, 8752-8762. doi: 10.1039/C8NR01286E

Lauth, J., Strupeit, T., Komowski, A., and Weller, H. (2013). A transmetalation route for colloidal GaAs nanocrystals and additional III-V semiconductor materials. Chem. Mater. 25, 1377-1383. doi: 10.1021/cm3019617

Li, D. Z., Peng, L. C., Zhang, Z. L., Shi, Z., Xie, R. G., Han, M. Y., et al. (2014). Large scale synthesis of air stable precursors for the preparation of high quality metal arsenide and phosphide nanocrystals as efficient emitters covering the visible to near infrared region. Chem. Mater. 26, 3599-3602. doi: 10.1021/cm500581m

Li, L., Protiere, M., and Reiss, P. (2008). Economic synthesis of high quality InP nanocrystals using calcium phosphide as the phosphorus precursor. Chem. Mater. 20, 2621-2623. doi: 10.1021/cm7035579

Li, L., and Reiss, P. (2008). One-pot synthesis of highly luminescent InP/ZnS nanocrystals without precursor injection. J. Am. Chem. Soc. 130, 11588-11589. doi: $10.1021 /$ ja $803687 \mathrm{e}$

Lim, J., Bae, W. K., Lee, D., Nam, M. K., Jung, J., Lee, C., et al. (2011). InP@ZnSeS, core@composition gradient shell quantum dots with enhanced stability. Chem. Mater. 23, 4459-4463. doi: 10.1021/cm201550w

Lim, J., Park, M., Bae, W. K., Lee, D., Lee, S., Lee, C., et al. (2013). Highly efficient cadmium-free quantum dot light-emitting diodes enabled by the direct formation of excitons within InP@ZnSeS quantum dots. ACS Nano 7, 9019-9026. doi: 10.1021/nn403594j

Lin, G. M., Ouyang, Q. L., Hu, R., Ding, Z. C., Tian, J. L., Yin, F., et al. (2015). In vivo toxicity assessment of non-cadmium quantum dots in BALB/c mice. Nanomed. Nanotechnol. Biol. Med. 11, 341-350. doi: 10.1016/j.nano.2014.10.002

Liu, J. F., Meyns, M., Zhang, T., Arbiol, J., Cabot, A., and Shavel, A. (2018). Triphenyl phosphite as the phosphorus source for the scalable and cost-effective production of transition metal phosphides. Chem. Mater. 30, 1799-1807. doi: 10.1021/acs.chemmater.8b00290

Liu, Z. K., Mu, H. R., Xiao, S., Wang, R. B., Wang, Z. T., Wang, W. W., et al. (2016). Pulsed lasers employing solution-processed plasmonic Cu3-xPcolloidal nanocrystals. Adv. Mater. 28, 3535-3542. doi: 10.1002/adma.201504927

Liu, Z. P., Kumbhar, A., Xu, D., Zhang, J., Sun, Z. Y., and Fang, J. Y. (2008). Coreduction colloidal synthesis of III-V nanocrystals: the case of InP. Angew. Chem. Int. Edn. 47, 3540-3542. doi: 10.1002/anie.200800281

Luber, E. J., Mobarok, M. H., and Buriak, J. M. (2013). Solution-processed zinc phosphide $(\alpha-\mathrm{Zn} 3 \mathrm{P} 2)$ colloidal semiconducting nanocrystals for thin film photovoltaic applications. ACS Nano 7, 8136-8146. doi: 10.1021/nn4034234 
Manna, G., Bose, R., and Pradhan, N. (2013). Semiconducting and plasmonic copper phosphide platelets. Angew. Chem. Int. Edn. 52, 6762-6766. doi: $10.1002 /$ anie.201210277

Miao, S., Yang, T., Hickey, S. G., Lesnyak, V., Rellinghaus, B., Xu, J. Z., et al. (2013). Emissive ZnO@Zn3P2 nanocrystals: synthesis, optical, and optoelectrochemical properties. Small 9, 3415-3422. doi: $10.1002 /$ smll.201203023

Miao, S. D., Hickey, S. G., Rellinghaus, B., Waurisch, C., and Eychmuller, A. (2010). Synthesis and characterization of cadmium phosphide quantum dots emitting in the visible red to near-infrared. J. Am. Chem. Soc. 132, 5613-5615. doi: $10.1021 /$ ja9105732

Miao, S. D., Hickey, S. G., Waurisch, C., Lesnyak, V., Otto, T., Rellinghaus, B., et al. (2012). Synthesis of monodisperse cadmium phosphide nanoparticles using ex-situ produced phosphine. ACS Nano 6, 7059-7065. doi: 10.1021/nn30 21037

Michalet, X., Pinaud, F. F., Bentolila, L. A., Tsay, J. M., Doose, S., Li, J. J., et al. (2005). Quantum dots for live cells, in vivo imaging, and diagnostics. Science 307, 538-544. doi: 10.1126/science.1104274

Micic, O. I., Cheong, H. M., Fu, H., Zunger, A., Sprague, J. R., Mascarenhas, A., et al. (1997). Size-dependent spectroscopy of InP quantum dots. J. Phys. Chem. B 101, 4904-4912. doi: 10.1021/jp9704731

Micic, O. I., Curtis, C. J., Jones, K. M., Sprague, J. R., and Nozik, A. J. (1994). Synthesis and characterization of InP quantum dots. J. Phys. Chem. 98, 4966-4969. doi: 10.1021/j100070a004

Micic, O. I., Sprague, J., Lu, Z. H., and Nozik, A. J. (1996). Highly efficient band-edge emission from InP quantum dots. Appl. Phys. Lett. 68, 3150-3152.

Micic, O. I., Sprague, J. R., Curtis, C. J., Jones, K. M., Machol, J. L., Nozik, A. J., et al. (1995). Synthesis and characterization of InP, GaP, and GalnP2 quantum dots. J. Phys. Chem. 99, 7754-7759.

Mobarok, M. H., Luber, E. J., Bernard, G. M., Peng, L., Wasylishen, R. E., and Buriak, J. M. (2014). Phase-pure crystalline zinc phosphide nanoparticles: synthetic approaches and characterization. Chem. Mater. 26, 1925-1935. doi: $10.1021 / \mathrm{cm} 500557 \mathrm{f}$

Mundy, M. E., Ung, D., Lai, N. L., Jahrman, E. P., Seidler, G. T., and Cossairt, B. M. (2018). Aminophosphines as versatile precursors for the synthesis of metal phosphide nanocrystals. Chem. Mater. 30, 5373-5379. doi: $10.1021 /$ acs.chemmater.8b02206

Nedelcu, G., Protesescu, L., Yakunin, S., Bodnarchuk, M. I., Grotevent, M. J., and Kovalenko, M. V. (2015). Fast anion-exchange in highly luminescentnanocrystals of cesium lead halide perovskites $(\mathrm{CsPbX} 3, \mathrm{X}=\mathrm{Cl}$, Br, I). Nano Lett. 15, 5635-5640. doi: 10.1021/acs.nanolett.5b02404

Ojo, W. S., Xu, S., Delpech, F., Nayral, C., and Chaudret, B. (2012). Roomtemperature synthesis of air-stable and size-tunable luminescent ZnS-coated Cd3P2 nanocrystals with high quantum yields. Angew. Chem. Int. Edn. 51, 738-741. doi: 10.1002/anie.201104864

Panfil, Y. E., Oded, M., and Banin, U. (2018). Colloidal quantum nanostructures: emerging materials for display applications. Angew. Chem. Int. Edn. 57, 4274-4295. doi: 10.1002/anie.201708510

Park, J., Koo, B., Yoon, K. Y., Hwang, Y., Kang, M., Park, J. G., et al. (2005). Generalized synthesis of metal phosphide nanorods via thermal decomposition of continuously delivered metal-phosphine complexes using a syringe pump. J. Am. Chem. Soc. 127, 8433-8440. doi: 10.1021/ja0427496

Perera, S. C., Fodor, P. S., Tsoi, G. M., Wenger, L. E., and Brock, S. L. (2003). Application of de-silylation strategies to the preparation of transition metal pnictide nanocrystals: the case of FeP. Chem. Mater. 15, 4034-4038. doi: $10.1021 / \mathrm{cm} 0344430$

Pietra, F., De Trizio, L., Hoekstra, A. W., Renaud, N., Prato, M., Grozema, F. C., et al. (2016). Tuning the lattice parameter of InxZnyP for highly luminescent lattice-matched core/shell quantum dots. ACS Nano 10, 4754-4762. doi: 10.1021/acsnano.6b01266

Pietra, F., Kirkwood, N., De Trizio, L., Hoekstra, A. W., Kleibergen, L., Renaud, N., et al. (2017). Ga for $\mathrm{Zn}$ cation exchange allows for highly luminescent and photostable InZnP-based quantum dots. Chem. Mater. 29, 5192-5199. doi: 10.1021/acs.chemmater.7b00848

Pietryga, J. M., Park, Y. S., Lim, J. H., Fidler, A. F., Bae, W. K., Brovelli, S., et al. (2016). Spectroscopic and device aspects of nanocrystal quantum dots. Chem. Rev. 116, 10513-10622. doi: 10.1021/acs.chemrev.6b00169
Pu, C., Qin, H., Gao, Y., Zhou, J., Wang, P., and Peng, X. (2017). Synthetic control of exciton behavior in colloidal quantum dots. J. Am. Chem. Soc. 139, 3302-3311. doi: 10.1021/jacs.6b11431

Qian, L., Zheng, Y., Xue, J. G., and Holloway, P. H. (2011). Stable and efficient quantum-dot light-emitting diodes based on solution-processed multilayer structures. Nat. Photo. 5, 543-548. doi: 10.1038/nphoton.2011.171

Rafipoor, M., Dupont, D., Tornatzky, H., Tessier, M. D., Maultzsch, J., Hens, Z., et al. (2018). Strain engineering in $\mathrm{InP} /(\mathrm{Zn}, \mathrm{Cd}) \mathrm{Se}$ core/shell quantum dots. Chem. Mater. 30, 4393-4400. doi: 10.1021/acs.chemmater.8b01789

Ramasamy, P., Kim, N., Kang, Y. S., Ramirez, O., and Lee, J. S. (2017). Tunable, bright, and narrow-band luminescence from colloidal indium phosphide quantum dots. Chem. Mater. 29, 6893-6899. doi: 10.1021/acs.chemmater.7b02204

Ramasamy, P., Ko, K. J., Kang, J. W., and Lee, J. S. (2018). Two-step "seedmediated" synthetic approach to colloidal indium phosphide quantum dots with high-purity photo- and electroluminescence. Chem. Mater. 30, 3643-3647. doi: 10.1021/acs.chemmater.8b02049

Reiss, P., Carriere, M., Lincheneau, C., Vaure, L., and Tamang, S. (2016). Synthesis of semiconductor nanocrystals, focusing on nontoxic and earth-abundant materials. Chem. Rev. 116, 10731-10819. doi: 10.1021/acs.chemrev.6b00116

Sahu, A., Kang, M. S., Kompch, A., Notthoff, C., Wills, A. W., Deng, D., et al. (2012). Electronic impurity doping in CdSe nanocrystals. Nano Lett. 12, 2587-2594. doi: $10.1021 / \mathrm{nl} 300880 \mathrm{~g}$

Shen, W., Tang, H. Y., Yang, X. L., Cao, Z. L., Cheng, T., Wang, X. Y., et al. (2017). Synthesis of highly fluorescent InP/ZnS small-core/thick-shell tetrahedralshaped quantum dots for blue light-emitting diodes. J. Mater. Chem. C 5, 8243-8249. doi: 10.1039/C7TC02927F

Song, W. S., Lee, H. S., Lee, J. C., Jang, D. S., Choi, Y., Choi, M., et al. (2013). Aminederived synthetic approach to color-tunable InP/ZnS quantum dots with high fluorescent qualities. J. Nanopart. Res. 15:1750. doi: 10.1007/s11051-013-1750-y

Steckel, J. S., Coe-Sullivan, S., Bulovic, V., and Bawendi, M. G. (2003). $1.3 \mu \mathrm{m}$ to $1.55 \mu \mathrm{m}$ tunable electroluminescence from $\mathrm{PbSe}$ quantum dots embedded within an organic device. Adv. Mater. 15, 1862-1866. doi: 10.1002/adma.200305449

Sun, T., Wang, Y. J., Yu, W. Z., Wang, Y. S., Dai, Z. G., Liu, Z. K., et al. (2017). Flexible broadband graphene photodetectors enhanced by plasmonic $\mathrm{Cu} 3-\mathrm{xP}$ colloidal nanocrystals. Small 13:1701881. doi: 10.1002/smll.201701881

Talapin, D. V., Lee, J. S., Kovalenko, M. V., and Shevchenko, E. V. (2010). Prospects of colloidal nanocrystals for electronic and optoelectronic applications. Chem. Rev. 110, 389-458. doi: 10.1021/cr900137k

Tamang, S., Lincheneau, C., Hermans, Y., Jeong, S., and Reiss, P. (2016). Chemistry of InP nanocrystal syntheses. Chem. Mater. 28, 2491-2506. doi: 10.1021/acs.chemmater.5b05044

Tessier, M. D., Baquero, E. A., Dupont, D., Grigel, V., Bladt, E., Bals, S., et al. (2018). Interfacial oxidation and photoluminescence of InP-based core/shell quantum dots. Chem. Mater. 30, 6877-6883. doi: 10.1021/acs.chemmater.8b03117

Tessier, M. D., De Nolf, K., Dupont, D., Sinnaeve, D., De Roo, J., and Hens, Z. (2016). Aminophosphines: a double role in the synthesis of colloidal indium phosphide quantum dots. J. Am. Chem. Soc. 138, 5923-5929. doi: $10.1021 /$ jacs.6b01254

Tessier, M. D., Dupont, D., De Nolf, K., De Roo, J., and Hens, Z. (2015). Economic and size-tunable synthesis of $\operatorname{InP} / \mathrm{ZnE}(\mathrm{E}=\mathrm{S}$, Se) colloidal quantum dots. Chem. Mater. 27, 4893-4898. doi: 10.1021/acs.chemmater.5b02138

Ung, T. D. T., Tran, T. T. H., Nguyen, Q. L., and Reiss, P. (2008). Low temperature synthesis of InP nanocrystals. Mater. Chem. Phys. 112, 1120-1123. doi: 10.1016/j.matchemphys.2008.07.051

Vinokurov, A., Chernysheva, G., Mordvinova, N., and Dorofeev, S. (2018). Optical properties and structure of Ag-doped InP quantum dots prepared by a phosphine synthetic route. Dalton Trans. 47, 12414-12419. doi: $10.1039 / \mathrm{C} 8 \mathrm{DT} 02434 \mathrm{~K}$

Wang, H. C., Zhang, H., Chen, H. Y., Yeh, H. C., Tseng, M. R., Chung, R. J., et al. (2017). Cadmium-free InP/ZnSeS/ZnS heterostructure-based quantum dot light-emitting diodes with a $\mathrm{ZnMgO}$ electron transport layer and a brightness of over $10000 \mathrm{~cd} \mathrm{~m}(-2)$. Small 13:1603962. doi: 10.1002/smll.201603962

Xie, R., Battaglia, D., and Peng, X. G. (2007). Colloidal InP nanocrystals as efficient emitters covering blue to near-infrared. J. Am. Chem. Soc. 129, 15432-15433. doi: $10.1021 / j a 076363 \mathrm{~h}$ 
Xie, R. G., Zhang, J. X., Zhao, F., Yang, W. S., and Peng, X. G. (2010). Synthesis of monodisperse, highly emissive, and size-tunable Cd3P2 nanocrystals. Chem. Mater. 22, 3820-3822. doi: 10.1021/cm1008653

Yang, W., He, G. X., Mei, S. L., Zhu, J. T., Zhang, W. L., Chen, Q. H., et al. (2017). Controllable synthesis of dual emissive Ag:InP/ZnS quantum dots with high fluorescence quantum yield. Appl. Surf. Sci. 423, 686-694. doi: 10.1016/j.apsusc.2017.06.048

Yang, X., Zhao, D. W., Leck, K. S., Tan, S. T., Tang, Y. X., Zhao, J. L., et al. (2012). Full visible range covering $\mathrm{InP} / \mathrm{ZnS}$ nanocrystals with high photometric performance and their application to white quantum dot light-emitting diodes. Adv. Mater. 24, 4180-4185. doi: 10.1002/adma.201104990

Zan, F., and Ren, J. C. (2012). Gas-liquid phase synthesis of highly luminescent $\mathrm{InP} / \mathrm{ZnS}$ core/shell quantum dots using zinc phosphide as a new phosphorus source. J. Mater. Chem. 22, 1794-1799. doi: 10.1039/C1JM13982G

Zhang, A. D., Dong, C. Q., Liu, H., and Ren, J. C. (2013). Blinking behavior of CdSe/CdS quantum dots controlled by alkylthiols as surface trap modifiers. J. Phys. Chem. C 117, 24592-24600. doi: 10.1021/jp408544x

Zhang, Z. L., Liu, D., Li, D. Z., Huang, K. K., Zhang, Y., Shi, Z., et al. (2015). Dual emissive Cu:InP/ZnS/InP/ZnS nanocrystals: single-source "greener"emitters with flexibly tunable emission from visible to near-infrared and their application in white lightemitting diodes. Chem. Mater. 27, 1405-1411. doi: 10.1021/cm50 47269

Ziegler, J., Xu, S., Kucur, E., Meister, F., Batentschuk, M., Gindele, F., et al. (2008). Silica-coated InP/ZnS nanocrystals as converter material in white LEDs. Adv. Mater. 20, 4068-4073. doi: 10.1002/adma.2008 00724

Conflict of Interest Statement: The authors declare that the research was conducted in the absence of any commercial or financial relationships that could be construed as a potential conflict of interest.

Copyright (c) $2019 \mathrm{Li}$, Jia, Meng and Li. This is an open-access article distributed under the terms of the Creative Commons Attribution License (CC BY). The use, distribution or reproduction in other forums is permitted, provided the original author(s) and the copyright owner(s) are credited and that the original publication in this journal is cited, in accordance with accepted academic practice. No use, distribution or reproduction is permitted which does not comply with these terms. 